\title{
Determination of the Evolution of Heterogeneous Single Metal Atoms and Nanoclusters under Reaction Conditions: Which Are the Working Catalytic Sites?
}

\author{
Lichen Liu, $^{\dagger}$ Debora M. Meira, ${ }^{\ddagger}{ }^{\S}$ Raul Arenal, ${ }^{\|, \perp, \# \odot ~}$ Patricia Concepcion, $^{\dagger \odot}$ Alberto V. Puga, ${ }^{\dagger, I I}$ \\ and Avelino Corma*,†
}

\begin{abstract}
†Instituto de Tecnología Química, Universitat Politécnica de València-Consejo Superior de Investigaciones Científicas (UPV-CSIC), Avenida de los Naranjos s/n, 46022 Valencia, Spain

${ }^{\ddagger}$ CLS@APS sector 20, Advanced Photon Source, Argonne National Laboratory, 9700 S. Cass Avenue, Argonne, Illinois 60439, United States

${ }^{\S}$ Canadian Light Source Inc., 44 Innovation Boulevard, Saskatoon, Saskatchewan S7N 2V3, Canada

"Laboratorio de Microscopias Avanzadas, Instituto de Nanociencia de Aragon, Universidad de Zaragoza, Mariano Esquillor Edificio I+D, 50018 Zaragoza, Spain

${ }^{\perp}$ ARAID Foundation, 50018 Zaragoza, Spain

\#Instituto de Ciencias de Materiales de Aragon, CSIC-Universidad de Zaragoza, C/Pedro Cerbuna 12, 50009 Zaragoza, Spain
\end{abstract}

\section{Supporting Information}

ABSTRACT: Identification of active sites in heterogeneous metal catalysts is critical for understanding the reaction mechanism at the molecular level and for designing more efficient catalysts. Because of their structural flexibility, subnanometric metal catalysts, including single atoms and clusters with a few atoms, can exhibit dynamic structural evolution when interacting with substrate molecules, making it difficult to determine the catalytically active sites. In this work, Pt catalysts containing selected types of Pt entities (from
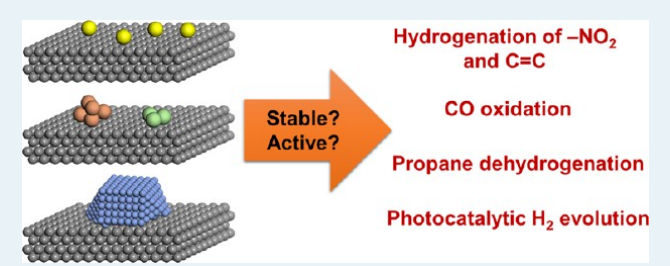
single atoms to clusters and nanoparticles) have been prepared, and their evolution has been followed, while they were reacting in a variety of heterogeneous catalytic reactions, including selective hydrogenation reactions, $\mathrm{CO}$ oxidation, dehydrogenation of propane, and photocatalytic $\mathrm{H}_{2}$ evolution reaction. By in situ X-ray absorption spectroscopy, in situ IR spectroscopy, and high-resolution electron microscopy techniques, we will show that some characterization techniques carried out in an inadequate way can introduce confusion on the interpretation of coordination environment of highly dispersed $\mathrm{Pt}$ species. Finally, the combination of catalytic reactivity and in situ characterization techniques shows that, depending on the catalyst-reactant interaction and metal-support interaction, singly dispersed metal atoms can rapidly evolve into metal clusters or nanoparticles, being the working active sites for those abovementioned heterogeneous reactions.

KEYWORDS: single-atom catalysis, subnanometric clusters, size effect, platinum, hydrogenation of nitroarenes, CO oxidation, propane dehydrogenation, photocatalytic $\mathrm{H}_{2}$ evolution

\section{INTRODUCTION}

Heterogeneous single-atom catalysts have attracted tremendous attention in the field of catalysis in recent years, and it has been shown in some reactions that single-atom catalysts present superior catalytic performance than the conventional nanoparticulate catalysts. ${ }^{1-3}$ The recent progress made in characterization tools on physicochemical properties has introduced further knowledge for better understanding catalysis at the atomic level. ${ }^{4,5}$ By decreasing the size of metal catalysts down to subnanometric metal clusters and even atomically dispersed species, the efficiency of a metal could be, in principle, maximized, and more importantly, unique catalytic behavior may appear associated with those atomically

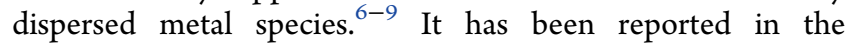
literature that, in some reactions, singly dispersed atoms are the active species, while clusters and nanoparticles are not. ${ }^{10,11}$ While in some works, metal clusters are found to be more active sites than single atoms and nanoparticles. ${ }^{12,13}$

However, to unambiguously conclude that singly dispersed metal atoms are the active species in the working catalysts is not an easy task, which can be reflected in some debates. For instance, $\mathrm{Pt}$ single atoms supported on $\mathrm{Al}_{2} \mathrm{O}_{3}, \mathrm{FeO}_{x}, \mathrm{TiO}_{2}$, and $\mathrm{CeO}_{2}$ are reported to be more active than $\mathrm{Pt}$ nanoparticles for $\mathrm{CO}$ oxidation, ${ }^{14-16}$ while in some other works, Pt atoms supported on zeolites or metal oxides are claimed to be less active than Pt nanoparticles. ${ }^{17}$ Similar issues have also been

Received: September 30, 2019

Revised: October 8, 2019

Published: October 25, 2019 

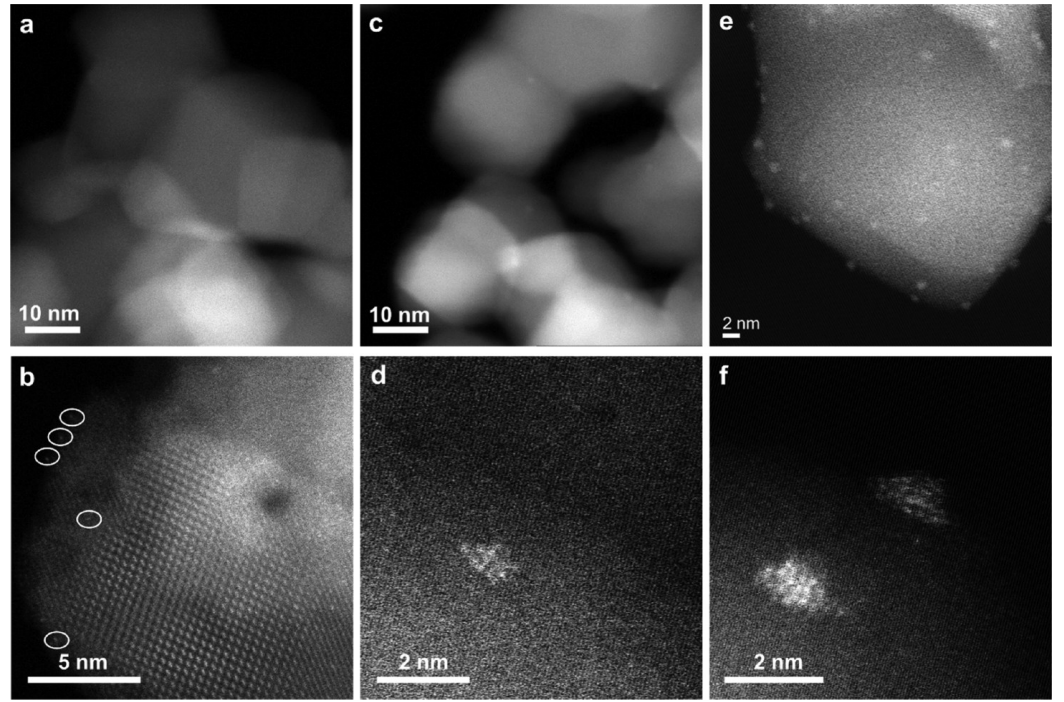

Figure 1. Characterization of $\mathrm{Pt} / \mathrm{TiO}_{2}$ catalysts with single atoms, clusters, and nanoparticles by $\mathrm{HR} \mathrm{HAADF}-\mathrm{STEM}$ imaging. $(\mathrm{a}, \mathrm{b}) 0.03 \mathrm{Pt} / \mathrm{TiO}{ }_{2}-$ SA sample containing singly dispersed $\mathrm{Pt}$ atoms. (c,d) $0.03 \mathrm{Pt} / \mathrm{TiO}_{2}-450 \mathrm{H}_{2}$ sample containing subnanometric $\mathrm{Pt}$ clusters. $(\mathrm{e}, \mathrm{f}) 0.2 \mathrm{Pt} / \mathrm{TiO}{ }_{2}-450 \mathrm{H}_{2}$ sample containing Pt nanoparticles.

reported with $\mathrm{Au}$ single-atom catalysts for $\mathrm{CO}$ oxidation. Singly dispersed $\mathrm{Au}$ atoms have been presented as efficient catalysts for CO oxidation, ${ }^{18,19}$ while others have shown that $\mathrm{Au}$ nanoclusters and nanoparticles supported on $\mathrm{CeO}_{2}$ are much more active than singly dispersed $\mathrm{Au}$ atoms. ${ }^{20,21}$ Singly dispersed $\mathrm{Pt}$ and $\mathrm{Pd}$ atoms on various supports have been reported as active catalysts for the hydrogenation of nitroarenes, olefins, and ketones. ${ }^{2-25}$ However, there are some publications showing that single $\mathrm{Pd}$ atoms supported on $\mathrm{FeO}_{x}$ show no activity in the hydrogenation of alkenes, while $\mathrm{Pd}$ clusters and nanoparticles on the same support are active. ${ }^{26}$

In most of the previous works, the catalytic performances of single atoms have been usually compared with nanoparticulate catalysts, without considering the presence of subnanometric metal clusters. As a transition state between single atoms and nanoparticles, metal clusters show distinct electronic and geometric structures compared to the other two entities, and consequently, a different catalytic behavior can be expected. $^{27,28}$ Indeed, it has been shown that subnanometric metal clusters can catalyze reactions that neither the singleatom nor nanoparticulate counterparts can. ${ }^{29-31}$ Therefore, it is necessary to study the size effect of the metal entities on catalysis by direct comparison of the catalytic performance of single atoms, clusters, and nanoparticles for establishing a structure-reactivity relationship. This is most relevant if one takes into account that metallic species can evolve during reaction conditions. Moreover, it should be considered that if single-atom catalysts and the nanoparticulate counterpart are prepared by different methodologies, additional uncertainty can be introduced into the studies, especially when considering the complexity of heterogeneous metal catalysts. ${ }^{32,33}$ Therefore, for a fair comparative study, the model catalysts should also be better prepared by the same method and the particle size of the metal species should be controlled by the synthesis parameters. Nevertheless, their potential evolution under reaction conditions should be followed that dynamic structural transformation can occur with atomically dispersed metal species and nanoclusters under reaction conditions. ${ }^{34,35}$ This is even more critical if one takes into consideration that a small fraction of single atoms or clusters within a supported metal catalyst formed by nanoparticles can be responsible for most of the catalyst activity. On the contrary, it may also occur that for some other reactions, a small fraction of metal clusters or nanoparticles present in the catalysts containing mainly single atoms contribute most to the catalytic reactivity. Then, the size of the metal particles and metal-support interaction will become more important and even determinant for the catalytic behavior, especially when referring to single atoms.

In this work, we have prepared by the same method a series of supported Pt catalysts with particle size ranging from singly dispersed atoms to clusters to nanoparticles on different supports $\left(\mathrm{TiO}_{2}, \mathrm{Al}_{2} \mathrm{O}_{3}\right.$, and $\left.\mathrm{CeO}_{2}\right)$. We have studied their catalytic performance for a variety of different reactions, including selective hydrogenation reactions, $\mathrm{CO}$ oxidation, propane dehydrogenation, and photocatalytic $\mathrm{H}_{2}$ evolution reaction. It has been found that Pt clusters and nanoparticles show higher activity than $\mathrm{Pt}$ single atoms in all the reactions studied. Furthermore, by in situ X-ray absorption spectroscopy (XAS),IR spectroscopy, and ex situ high-resolution scanning transmission electron microscopy (HR STEM), we have observed that the structural transformation of single $\mathrm{Pt}$ atoms under reaction conditions depends not only on the nature of the reactants but also on the material acting as the support. In other words, metal-reactant and metal-support interactions not only dictate the geometric and electronic properties of the metal entities, and therefore the catalytic behavior, but also are determinant for the evolution behavior of subnanometric metal species under the reaction conditions.

\section{RESULTS AND DISCUSSION}

2.1. Pt Single Atoms, Clusters, and Nanoparticles for Hydrogenation Reactions. First, we have prepared a series of $\mathrm{Pt} / \mathrm{TiO}_{2}$ catalysts by conventional wetness impregnation (see the Supporting Information for experimental details), and the size of Pt species supported on $\mathrm{TiO}_{2}$ was controlled by the Pt loading and the treatments during the preparation procedure. As shown in Figure 1a,b, Pt single atoms supported on $\mathrm{TiO}_{2}$ (named as $0.03 \mathrm{Pt} / \mathrm{TiO}_{2}$-SA with 0.03 wt $\%$ of $\mathrm{Pt}$ ) were directly observed by HR high-angle annular dark-field STEM (HR HAADF-STEM). After reduction by $\mathrm{H}_{2}$ at 450 
${ }^{\circ} \mathrm{C}$, those singly dispersed $\mathrm{Pt}$ atoms agglomerated into $\mathrm{Pt}$ clusters of ca. $0.5-1.0 \mathrm{~nm}$ (see Figures 1c,d and S1). The average size of $\mathrm{Pt}$ particles was found to be subnanometric when the sample contained 0.1 wt \% of Pt (see Figure S2). When the $\mathrm{Pt}$ loading was increased to $0.2 \mathrm{wt} \%, \mathrm{Pt}$ nanoparticles of $\sim 1 \mathrm{~nm}$ were obtained after reduction by $\mathrm{H}_{2}$ at $450{ }^{\circ} \mathrm{C}$ (see Figures 1e,f and S3). When the Pt loading was further increased to $0.5 \mathrm{wt} \%$, Pt nanoparticles of $\sim 1.5 \mathrm{~nm}$ were formed on $\mathrm{TiO}_{2}$ (see Figure S4). These STEM images suggest that $\mathrm{Pt}$ clusters and nanoparticles with good dispersion and narrow size distributions can be generated on $\mathrm{TiO}_{2}$ and that their particle size can be tuned by $\mathrm{Pt}$ loading and reduction treatment. Therefore, we can use these $\mathrm{Pt} / \mathrm{TiO}_{2}$ catalysts as model catalysts to study the size effect on their catalytic properties for different reactions.

The hydrogenation of 3-nitrostyrene was chosen as the first model reaction to study the catalytic performance of different types of $\mathrm{Pt}$ species because it can be carried out at low temperature to avoid the potential effect of reaction temperature on the size of $\mathrm{Pt}$ particles and also because its catalytic behavior versus the particle size of metal nanoparticles has been widely reported. ${ }^{36-39}$ As shown in Figure 2, the Pt single

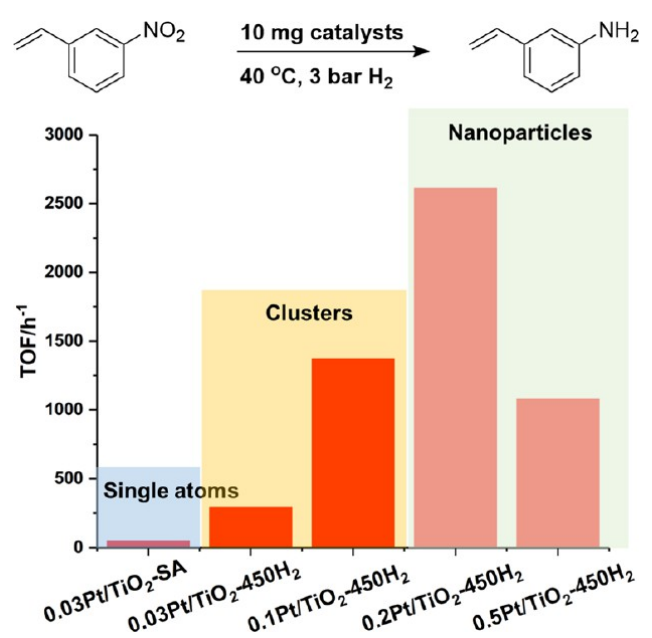

Figure 2. Catalytic performance of different Pt species supported on $\mathrm{TiO}_{2}$ for the hydrogenation of 3-nitrostyrene. Reaction conditions: $0.5 \mathrm{mmol}$ of 3-nitrostyrene, $2 \mathrm{~mL}$ of toluene as the solvent, $10 \mathrm{mg}$ of solid catalyst, $40{ }^{\circ} \mathrm{C}$ and 3 bar of $\mathrm{H}_{2}$. High selectivity to 3aminostyrene has been achieved for all the $\mathrm{Pt} / \mathrm{TiO}_{2}$ samples containing Pt clusters and nanoparticles. The TOF shown in this figure was calculated based on the total Pt amount in all the samples.

atoms show negligible activity. It should be mentioned that $\mathrm{Pt}$ single atoms supported on $\mathrm{TiO}_{2}$ remain stable after the hydrogenation of 3-nitrostyrene (see Figure S5), indicating the stability of single $\mathrm{Pt}$ atoms under mild reaction conditions. In the case of $\mathrm{Pt} / \mathrm{TiO}_{2}$ catalysts containing a large fraction of metal atoms within the subnanometric clusters of ca. $0.4-0.8$ $\mathrm{nm}$ (the $0.03 \% \mathrm{Pt} / \mathrm{TiO}_{2}-450 \mathrm{H}_{2}$ and $0.1 \% \mathrm{Pt} / \mathrm{TiO}_{2}-450 \mathrm{H}_{2}$ samples), the activity is significantly higher than the samples formed by $\mathrm{Pt}$ single atoms. Further increasing the Pt particle size to $\sim 1 \mathrm{~nm}$ will result in a higher intrinsic activity for chemoselective hydrogenation of 3-nitrostyrene to 3-aminostyrene, with a turnover frequency (TOF) of $\sim 2600 \mathrm{~h}^{-1}$, which is higher than any other catalyst reported so far in the literature at the same temperature and $\mathrm{H}_{2}$ pressure. It should be noted that the TOF values were calculated based on the total $\mathrm{Pt}$ amount in the catalysts, as in the literature. ${ }^{22}$ Moreover, further increasing the size of $\mathrm{Pt}$ nanoparticles to $\sim 1.5 \mathrm{~nm}$ (the $0.5 \%$ $\mathrm{Pt} / \mathrm{TiO}_{2}-450 \mathrm{H}_{2}$ sample) leads to a drop of the TOF, suggesting that $\mathrm{Pt}$ nanoparticles of $\sim 1 \mathrm{~nm}$ formed by 30-40 atoms are the most active species for the hydrogenation of 3nitrostyrene under our conditions.

In our previous work, it has been proposed that when $\mathrm{Pt}$ nanoparticles were partially covered by $\mathrm{TiO}_{2}$ overlayers, they were the active sites for chemoselective hydrogenation of nitroarenes in $\mathrm{Pt} / \mathrm{TiO}_{2}$ catalysts. ${ }^{40}$ Herein, we have studied this effect on the $0.2 \mathrm{Pt} / \mathrm{TiO}_{2}-450 \mathrm{H}_{2}$ sample. With the help of $\mathrm{HR}$ HAADF-STEM imaging and electron energy loss spectroscopy (EELS) mapping, we were able to obtain information on the structure of those small Pt particles $(\sim 1 \mathrm{~nm})$ at the atomic level. In fact, these techniques are likely the most appropriate techniques to perform such kind of analyses. ${ }^{41-43}$ As displayed in Figure 3, the hemispherical Pt nanoparticles are surrounded by $\mathrm{TiO}_{2}$ layers and the exposed surface area for each $\mathrm{Pt}$ nanoparticle is less than $1 \times 1 \mathrm{~nm}$ (see more EELS mapping results in Figures S6 and S7). In other words, because of the strong metal-support interaction between $\mathrm{Pt}$ and $\mathrm{TiO}_{2}$, only a few $\mathrm{Pt}$ atoms are exposed to the reactants, and these "cluster"type $\mathrm{Pt}$ sites, in the $\mathrm{Pt}$ nanoparticles partially covered by $\mathrm{TiO}_{2}$ overlayers, are the active sites for chemoselective hydrogenation of nitroarenes.

Considering that $\mathrm{H}_{2}$ activation is a key step for the hydrogenation of 3-nitrostyrene, we have measured the $\mathrm{H}_{2}-$ $\mathrm{D}_{2}$ exchange to correlate the capability of the $\mathrm{Pt}$ single atoms, clusters, and nanoparticles for $\mathrm{H}_{2}$ activation. ${ }^{44}$ As shown in Figure $\mathrm{S} 8$, both the $0.03 \mathrm{Pt} / \mathrm{TiO}_{2}-\mathrm{SA}$ sample containing single $\mathrm{Pt}$ atoms and $0.03 \mathrm{Pt} / \mathrm{TiO}_{2}-450 \mathrm{H}_{2}$ containing $\mathrm{Pt}$ clusters show clearly lower reactivity for $\mathrm{H}_{2}-\mathrm{D}_{2}$ exchange at room temperature than the $0.2 \mathrm{Pt} / \mathrm{TiO}_{2}-450 \mathrm{H}_{2}$ sample containing $\mathrm{Pt}$ nanoparticles of $\sim 1 \mathrm{~nm}$. These results indicate that $\mathrm{Pt}$ nanoparticles show higher capability for the activation of $\mathrm{H}_{2}$ than single atoms and subnanometric clusters, which can explain the higher activity of the former for the hydrogenation of 3-nitrostyrene. It should be mentioned that, in a recent work, $\mathrm{Pd}_{3}$ clusters are claimed to be much more active than single $\mathrm{Pd}$ atoms and $\mathrm{Pd}_{2}$ dimers for the hydrogenation of alkynes. ${ }^{45}$ Though the catalytic performance of Pd particles with larger sizes is not studied in that work, the higher reactivity of metal particles with multiple atoms than single atoms for hydrogenation reactions is consistent with our findings in this work.

The drop in the activity for Pt nanoparticles of $\sim 1.5 \mathrm{~nm}$ or larger may be related with the electronic interaction between $\mathrm{Pt}$ and the $\mathrm{TiO}_{2}$ support. Lykhach et al. have demonstrated that the electronic charge transfer between $\mathrm{Pt}$ and $\mathrm{CeO}_{2}$ reaches the maximum for $\mathrm{Pt}$ nanoparticles of $\sim 50$ atoms. ${ }^{46}$ In our case, the strong metal-support interaction between $\mathrm{Pt}$ and $\mathrm{TiO}_{2}$ could be dependent on the particle size of $\mathrm{Pt}$ and the coverage of $\mathrm{TiO}_{2}$ overlayers on the Pt nanoparticles may vary with the particle size of $\mathrm{Pt}$, resulting in difference in the electronic and geometric structure of $\mathrm{Pt}$ species. ${ }^{47}$ For that reason, $\mathrm{Pt}$ particles in the $0.2 \mathrm{Pt} / \mathrm{TiO}_{2}-450 \mathrm{H}_{2}$ sample are much more active than the $0.03 \mathrm{Pt} / \mathrm{TiO}_{2}-450 \mathrm{H}_{2}$ sample containing $\mathrm{Pt}$ clusters. Because of the electronic and geometric factors, the $\mathrm{Pt} / \mathrm{TiO}_{2}$ sample with $\mathrm{Pt}$ nanoparticles of $\sim 1 \mathrm{~nm}$ partially covered by $\mathrm{TiO}_{2}$ overlayers shows both high activity and chemoselectivity for the hydrogenation of nitroarenes, while $\mathrm{Pt}$ single atoms and small Pt clusters are sensibly less active. 
a

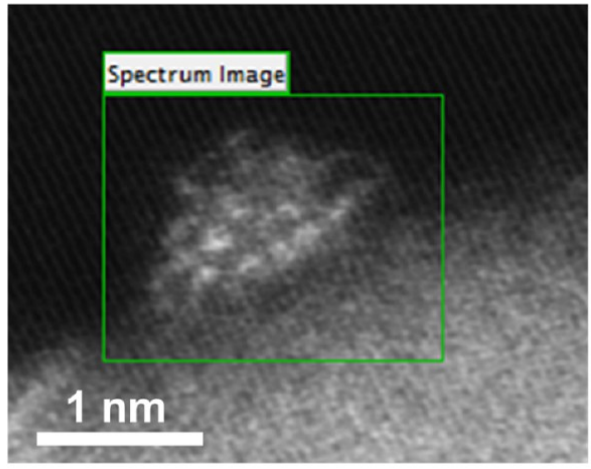

b

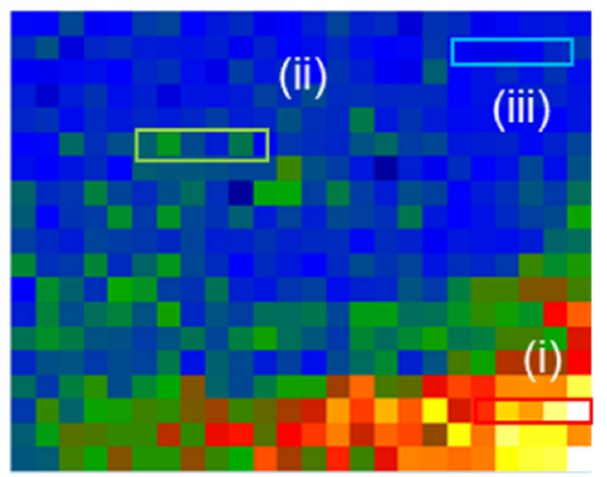

C

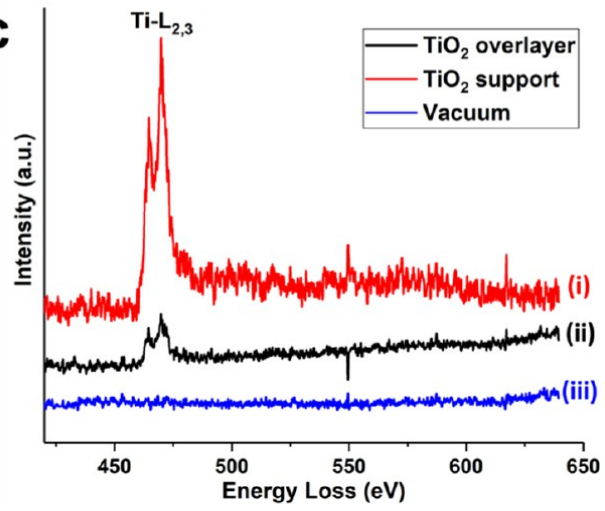

Figure 3. Atomic structure of the $0.2 \mathrm{Pt} / \mathrm{TiO}_{2}-450 \mathrm{H}_{2}$ sample by $\mathrm{HR}$ HAADF-STEM and EELS spectroscopy. (a) Typical HAADFSTEM image of the Pt nanoparticle supported on $\mathrm{TiO}_{2}$ with atomic resolution. (b) EELS mapping of the Ti-L edge in the selected area shown in (a). (c) Ti- $\mathrm{L}_{2,3}$ edge EELS spectra of three different areas shown in (b).

To compare the catalytic properties of different $\mathrm{Pt}$ entities on other supports with weak metal-support interaction, we have also prepared a series of $\mathrm{Pt} / \mathrm{Al}_{2} \mathrm{O}_{3}$ samples containing $\mathrm{Pt}$ ranging from single atoms to clusters and nanoparticles. First, a $0.2 \mathrm{Pt} / \mathrm{Al}_{2} \mathrm{O}_{3}-\mathrm{SA}$ sample containing $\mathrm{Pt}$ single atoms was prepared by impregnation according to the literature. ${ }^{48}$ As shown in Figures 4a,b and S9, only singly dispersed Pt atoms can be observed in the HR STEM images of the $\mathrm{Pt} / \mathrm{Al}_{2} \mathrm{O}_{3}-\mathrm{SA}$ sample. After reduction by $\mathrm{H}_{2}$ at $200{ }^{\circ} \mathrm{C}$, some of the single $\mathrm{Pt}$ atoms agglomerate into $\mathrm{Pt}$ clusters, while there are still some single $\mathrm{Pt}$ atoms preserved in the $0.2 \mathrm{Pt} / \mathrm{Al}_{2} \mathrm{O}_{3}-200 \mathrm{H}_{2}$ sample (see Figures $4 \mathrm{c}, \mathrm{d}$ and $\mathrm{S} 10$ ). When raising the reduction temperature to $300{ }^{\circ} \mathrm{C}$ (see Figure S11) and $450{ }^{\circ} \mathrm{C}$ (see Figures $4 \mathrm{e}, \mathrm{f}$ and $\mathrm{S} 12$ ), the fraction of single $\mathrm{Pt}$ atoms in the reduced $\mathrm{Pt} / \mathrm{Al}_{2} \mathrm{O}_{3}$ decreases and only very few $\mathrm{Pt}$ atoms can still be found in the $0.2 \mathrm{Pt} / \mathrm{Al}_{2} \mathrm{O}_{3}-450 \mathrm{H}_{2}$ sample. Therefore, the percentage of $\mathrm{Pt}$ single atoms can be modulated by the
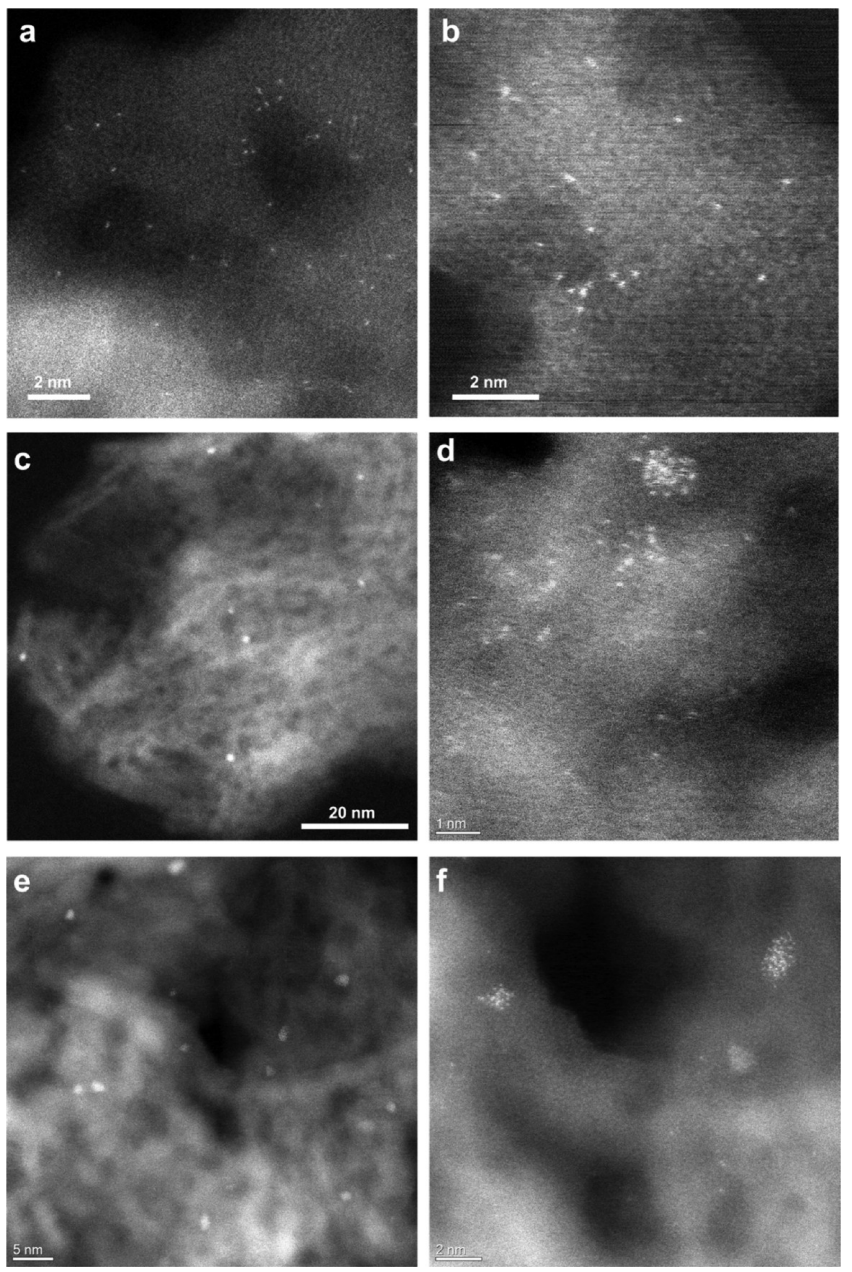

Figure 4. $\mathrm{Pt} / \mathrm{Al}_{2} \mathrm{O}_{3}$ samples with different types of $\mathrm{Pt}$ species. HR HAADF-STEM images of $\mathrm{Pt} / \mathrm{Al}_{2} \mathrm{O}_{3}$-SA $(\mathrm{a}, \mathrm{b})$ containing only singly dispersed $\mathrm{Pt}$ atoms, $\mathrm{Pt} / \mathrm{Al}_{2} \mathrm{O}_{3}-200 \mathrm{H}_{2}$ (c,d) containing a mixture of both singly $\mathrm{Pt}$ atoms and $\mathrm{Pt}$ nanoclusters, and $\mathrm{Pt} / \mathrm{Al}_{2} \mathrm{O}_{3}-450 \mathrm{H}_{2}$ (e,f) containing mainly $\mathrm{Pt}$ nanoparticles and a few singly dispersed $\mathrm{Pt}$ atoms.

reduction temperature, and these $\mathrm{Pt} / \mathrm{Al}_{2} \mathrm{O}_{3}$ samples can also be model catalysts for the direct comparison between single $\mathrm{Pt}$ atoms, clusters, and nanoparticles.

The chemical states and coordination environment of $\mathrm{Pt}$ species supported on $\mathrm{Al}_{2} \mathrm{O}_{3}$ obtained after different treatments were characterized by XAS. As shown in Figure 5a and Table 1, when the $\mathrm{Pt} / \mathrm{Al}_{2} \mathrm{O}_{3}$ samples were directly measured by XAS without any treatments, all the three $\mathrm{Pt} / \mathrm{Al}_{2} \mathrm{O}_{3}$ samples present oxidized states as revealed by $\mathrm{X}$-ray absorption near-edge structure (XANES), though the $0.2 \mathrm{Pt} / \mathrm{Al}_{2} \mathrm{O}_{3}-200 \mathrm{H}_{2}$ and $0.2 \mathrm{Pt} / \mathrm{Al}_{2} \mathrm{O}_{3}-450 \mathrm{H}_{2}$ samples were previously reduced by $\mathrm{H}_{2}$. The oxidized state of $\mathrm{Pt}$ in the two previously reduced samples should be caused by the reoxidation of $\mathrm{Pt}$ clusters or small $\mathrm{Pt}$ nanoparticles when exposed to air after the $\mathrm{H}_{2}$ reduction treatment. The oxidized nature of these samples was further confirmed by the extended X-ray absorption fine structure (EXAFS) spectra (see Figure $5 \mathrm{~b}$ ). The $\mathrm{Pt}-\mathrm{O}$ contribution in the $\mathrm{Pt} / \mathrm{Al}_{2} \mathrm{O}_{3}$ samples may come from $\mathrm{O}$ in the $\mathrm{Al}_{2} \mathrm{O}_{3}$ support and the oxygen directly bonded to Pt atoms. ${ }^{48}$ The presence of $\mathrm{Pt}-\mathrm{Al}$ contribution in the EXAFS fit results can be ascribed to the interaction between small $\mathrm{Pt}$ particles and $\mathrm{Al}_{2} \mathrm{O}_{3}{ }^{48,49}$ Interestingly, the $0.2 \mathrm{Pt} / \mathrm{Al}_{2} \mathrm{O}_{3}-200 \mathrm{H}_{2}$ sample almost shows the 

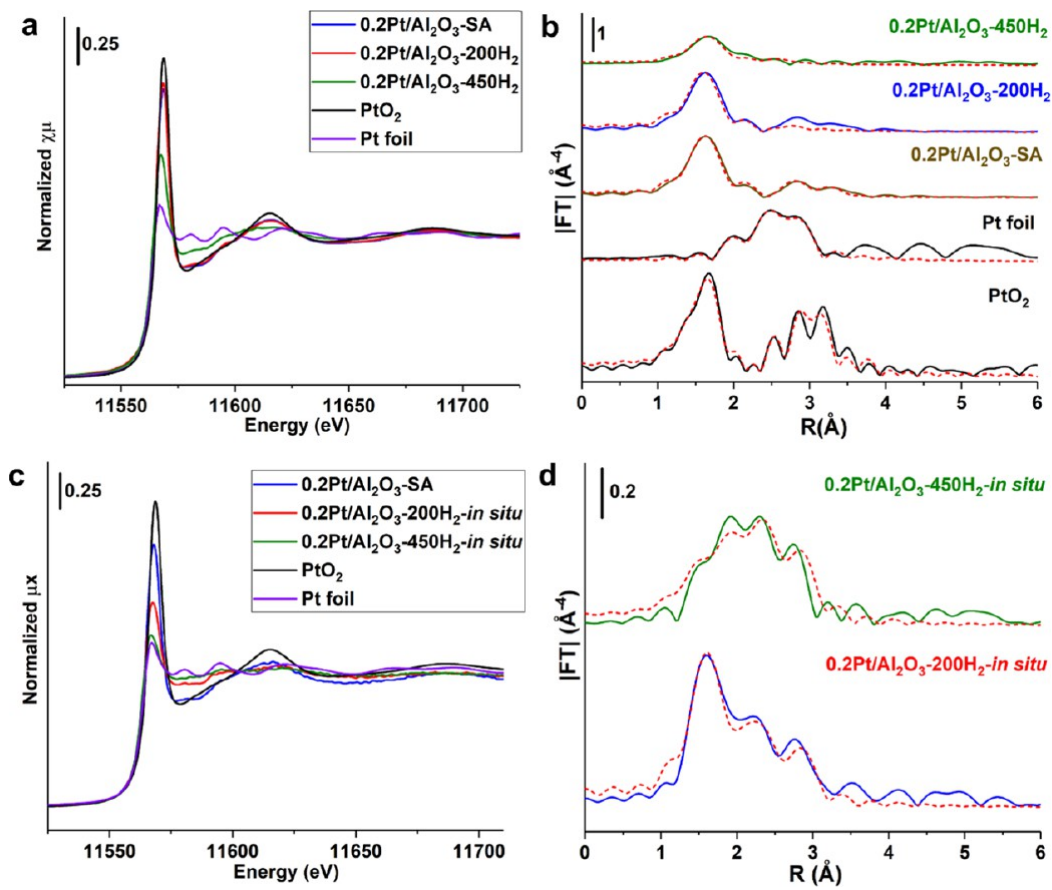

Figure 5. Characterizations of $\mathrm{Pt} / \mathrm{Al}_{2} \mathrm{O}_{3}$ samples by XAS. (a) XANES spectra and (b) EXAFS spectra (not phase-corrected) of the as-prepared Pt/ $\mathrm{Al}_{2} \mathrm{O}_{3}-\mathrm{SA}, \mathrm{Pt} / \mathrm{Al}_{2} \mathrm{O}_{3}-200 \mathrm{H}_{2}$, and $\mathrm{Pt} / \mathrm{Al}_{2} \mathrm{O}_{3}-450 \mathrm{H}_{2}$ samples. The spectra presented in $(\mathrm{a}, \mathrm{b})$ were directly recorded without any treatments in the synchrotron. (c) XANES spectra and (d) EXAFS spectra (not phase-corrected) of the $\mathrm{Pt} / \mathrm{Al}_{2} \mathrm{O}_{3}-200 \mathrm{H}_{2}$ and $\mathrm{Pt} / \mathrm{Al}_{2} \mathrm{O}_{3}-450 \mathrm{H}_{2}$ samples obtained after in situ reduction treatment in the synchrotron. The fit curves of the EXAFS spectra are presented as dashed red curves in (b,d).

Table 1. Fit Results the EXAFS Spectra of $\mathrm{Pt} / \mathrm{Al}_{2} \mathrm{O}_{3}$ Samples Prepared under Different Conditions ${ }^{a}$

\begin{tabular}{|c|c|c|c|c|c|c|c|c|c|}
\hline \multirow[b]{2}{*}{ sample } & \multicolumn{3}{|c|}{$\mathrm{Pt}-\mathrm{O}$} & \multicolumn{3}{|c|}{$\mathrm{Pt}-\mathrm{Pt}$} & \multicolumn{3}{|c|}{$\mathrm{Pt}-\mathrm{Al}$} \\
\hline & $\mathrm{CN}_{\mathrm{Pt}-\mathrm{O}}$ & $R(\AA)$ & $\sigma^{2}\left(\AA^{2}\right)$ & $\overline{\mathrm{CN}_{\mathrm{Pt}-\mathrm{Pt}}}$ & $R(\AA)$ & $\sigma^{2}\left(\AA^{2}\right)$ & $\overline{\mathrm{CN}_{\mathrm{Pt}-\mathrm{Al}}}$ & $R(\AA)$ & $\sigma^{2}\left(\AA^{2}\right)$ \\
\hline Pt foil & & & & 12 & 2.77 & & & & \\
\hline $\mathrm{PtO}_{2}$ & 6 & 1.99 & & & & & & & \\
\hline $0.2 \mathrm{Pt} / \mathrm{Al}_{2} \mathrm{O}_{3}-\mathrm{SA}^{b}$ & $6.2 \pm 0.9$ & $2.00 \pm 0.01$ & $0.003 \pm 0.002$ & & & & $3 \pm 2$ & $2.92 \pm 0.05$ & 0.01 \\
\hline $0.2 \mathrm{Pt} / \mathrm{Al}_{2} \mathrm{O}_{3}-200 \mathrm{H}_{2}^{b}$ & $5.7 \pm 0.9$ & $1.99 \pm 0.01$ & $0.002 \pm 0.002$ & & & & $2 \pm 1$ & $2.90 \pm 0.07$ & 0.01 \\
\hline $0.2 \mathrm{Pt} / \mathrm{Al}_{2} \mathrm{O}_{3}-450 \mathrm{H}_{2}^{b}$ & $3.0 \pm 0.6$ & $2.01 \pm 0.01$ & $0.003 \pm 0.003$ & $3 \pm 1$ & $2.76 \pm 0.03$ & 0.01 & & & \\
\hline $0.2 \mathrm{Pt} / \mathrm{Al}_{2} \mathrm{O}_{3}-200 \mathrm{H}_{2}-\mathrm{in} \mathrm{situ}^{c}$ & $2.0 \pm 0.5$ & $1.99 \pm 0.01$ & $0.003 \pm 0.003$ & $5 \pm 2$ & $2.75 \pm 0.02$ & $0.009 \pm 0.004$ & & & \\
\hline $0.2 \mathrm{Pt} / \mathrm{Al}_{2} \mathrm{O}_{3}-450 \mathrm{H}_{2}-$ in situ $^{c}$ & $2 \pm 1$ & $2.01 \pm 0.04$ & $0.01 \pm 0.02$ & $7 \pm 2$ & $2.72 \pm 0.01$ & $0.009 \pm 0.003$ & & & \\
\hline
\end{tabular}

${ }^{a} \Delta E_{0}=9, R_{\text {factor }}=0.7$. To decrease the number of parameters, the Debye-Waller $\left(\sigma^{2}\right)$ was kept free but the same for all paths with exception of the second shell contribution in the $\mathrm{Pt} / \mathrm{Al}_{2} \mathrm{O}_{3}$ samples measured directly. In this case, it was fixed to $0.01 .{ }^{b} \mathrm{The}$ sample was directly measured by XAS without any treatment. ${ }^{c}$ The sample was reduced by $\mathrm{H}_{2}$ at a given temperature before the XAS measurement.

same EXAFS spectrum as the $0.2 \mathrm{Pt} / \mathrm{Al}_{2} \mathrm{O}_{3}$-SA sample, though the size of Pt species in these two samples is quite different, as presented in the above STEM images. A large number of $\mathrm{Pt}$ clusters were observed in the STEM images, while the presence of these species was not reflected in the EXAFS results (see Table 1 for the fit results). The absence of $\mathrm{Pt}-\mathrm{Pt}$ contribution in the EXAFS spectrum of the directly measured $0.2 \mathrm{Pt} / \mathrm{Al}_{2} \mathrm{O}_{3}-200 \mathrm{H}_{2}$ sample could be caused by the complete oxidation of $\mathrm{Pt}$ clusters into $\mathrm{PtO}_{x}$ clusters by air. It has been observed in the literature that $\mathrm{PtO}_{x}$ clusters or small $\mathrm{PtO}_{x}$ nanoparticles $(<5 \mathrm{~nm})$ can show similar EXAFS spectra as singly dispersed $\mathrm{Pt}$ atoms on metal oxide supports because of the high degree of disorder of the small platinum oxide particles. ${ }^{50-52}$ Notably, when $0.2 \mathrm{Pt} / \mathrm{Al}_{2} \mathrm{O}_{3}-200 \mathrm{H}_{2}$ and $0.2 \mathrm{Pt} /$ $\mathrm{Al}_{2} \mathrm{O}_{3}-450 \mathrm{H}_{2}$ were in situ reduced by $\mathrm{H}_{2}$ before the XAS measurement, the oxidized Pt clusters or nanoparticles became partially reduced, as shown in the XANES spectra (see Figure 5c). The presence of Pt-Pt contribution at $2.7 \AA$ can also be confirmed in the EXAFS spectra (see Figure $5 \mathrm{~d}$ ) and by the corresponding fit results. The above XAS results indicate that subnanometric $\mathrm{Pt}$ clusters can be easily oxidized to corresponding $\mathrm{PtO}_{x}$ clusters and that the oxidized species may show similar feature as the $\mathrm{Pt}$ single-atom species in EXAFS spectra if the sample is measured directly without in situ prereduction treatment.

The importance of utilization of in situ XAS to characterize the chemical states and coordination environment of supported Pt catalysts has also been reflected in the case of the $\mathrm{Pt} / \mathrm{TiO}_{2}$ sample containing $\mathrm{Pt}$ nanoparticles of $\sim 1 \mathrm{~nm}$. As shown in Figure S13, when $0.2 \mathrm{Pt} / \mathrm{TiO}_{2}-450 \mathrm{H}_{2}$ was measured directly by XAS without any pretreatment, the XANES spectrum corresponding to partially oxidized Pt species was observed. The presence of the $\mathrm{Pt}-\mathrm{O}$ contribution at $\sim 2.0 \AA$ in the EXAFS spectrum (Figure S14) of the directly measured $0.2 \mathrm{Pt} / \mathrm{TiO}_{2}-450 \mathrm{H}_{2}$ sample indicated that $\mathrm{Pt}$ seemed to be atomically dispersed, which was inconsistent with the STEM images shown in Figure 1. As discussed above, the reoxidation of $\mathrm{Pt}$ particles by air can cause the transformation of small 

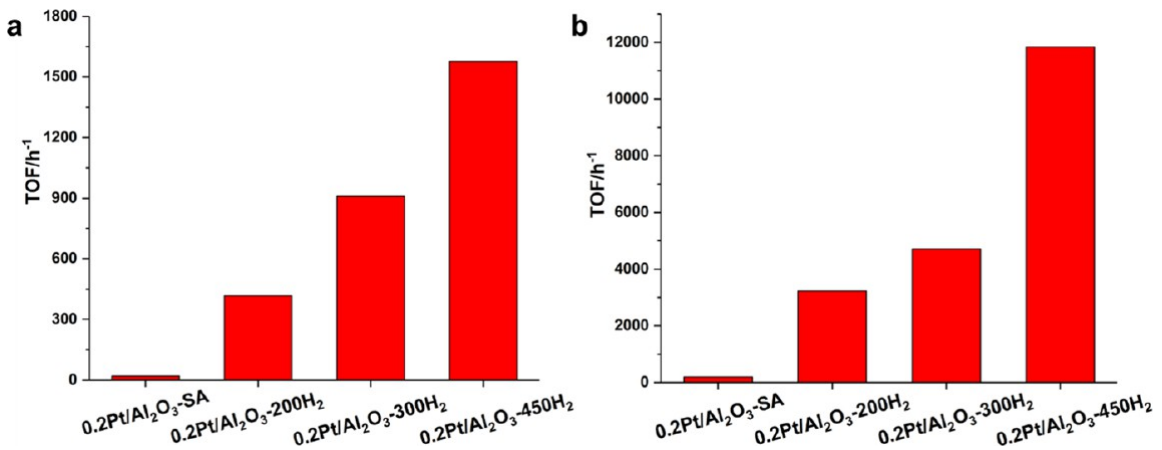

Figure 6. Catalytic performance of $\mathrm{Pt} / \mathrm{Al}_{2} \mathrm{O}_{3}$ catalysts for hydrogenation reactions. (a) Hydrogenation of 3-nitrostyrene with various $\mathrm{Pt} / \mathrm{Al}_{2} \mathrm{O}_{3}$ catalysts. Reaction conditions: $0.5 \mathrm{mmol}$ of 3-nitrostyrene, $2 \mathrm{~mL}$ of toluene as the solvent, $20 \mathrm{mg}$ of solid catalyst, $50{ }^{\circ} \mathrm{C}$ and $3 \mathrm{bar}$ of $\mathrm{H}_{2}$. The product distributions of the hydrogenation of 3-nitrostyrene with $\mathrm{Pt} / \mathrm{Al}_{2} \mathrm{O}_{3}$ catalysts are shown in Figure S16. (b) Hydrogenation of styrene with various $\mathrm{Pt} / \mathrm{Al}_{2} \mathrm{O}_{3}$ catalysts. Reaction conditions: $1.0 \mathrm{mmol}$ of styrene, $2 \mathrm{~mL}$ of toluene as the solvent, $10 \mathrm{mg}$ of solid catalyst, $50{ }^{\circ} \mathrm{C}$ and $3 \mathrm{bar}$ of $\mathrm{H}_{2}$. The TOF in this figure was calculated based on the total $\mathrm{Pt}$ amount in all the $\mathrm{Pt} / \mathrm{Al}_{2} \mathrm{O}_{3}$ samples.

metallic Pt nanoparticles into disordered $\mathrm{PtO}_{x}$ particles, which may be inadequately interpreted as singly dispersed $\mathrm{Pt}$ atoms. Notably, after in situ reduction treatment by $\mathrm{H}_{2}$ at $50{ }^{\circ} \mathrm{C}$, significant reduction of $\mathrm{PtO}_{x}$ into metallic $\mathrm{Pt}$ was observed in the XANES spectrum, and the Pt-Pt bonding at $\sim 2.7 \AA$ was also detected in the EXAFS spectrum. More interestingly, when the prereduction temperature was increased to $450{ }^{\circ} \mathrm{C}$, a higher contribution of $\mathrm{Pt}-\mathrm{O}$ bonding was observed in the EXAFS compared to the spectrum obtained after prereduction treatment at lower temperatures (see fit results in Table S1). The observation of the increased $\mathrm{Pt}-\mathrm{O}$ contribution can be associated with the formation of $\mathrm{TiO}_{2}$ overlayers on the surface of $\mathrm{Pt}$ nanoparticles because of the strong metal-support interaction. ${ }^{53}$ On the basis of the EXAFS characterization results on $\mathrm{Pt} / \mathrm{Al}_{2} \mathrm{O}_{3}$ and $\mathrm{Pt} / \mathrm{TiO}_{2}$ samples, we can conclude that because of their high reactivity with $\mathrm{O}_{2}$, the characterization techniques using in situ treatment facilities are necessary to obtain reliable information on the chemical states and coordination environment of supported Pt clusters or small nanoparticles.

Catalytic Behavior of Pt Single Atoms Supported on $\mathrm{Al}_{2} \mathrm{O}_{3}$ for Hydrogenation Reactions. First, we have tested the catalytic performance of $\mathrm{Pt} / \mathrm{Al}_{2} \mathrm{O}_{3}$ catalysts for the hydrogenation of 3-nitrostyrene. As shown in Figure 6a, similar to the situation of $\mathrm{Pt} / \mathrm{TiO}_{2}$ catalysts, the $0.2 \mathrm{Pt} / \mathrm{Al}_{2} \mathrm{O}_{3}$ SA sample shows negligible activity for the hydrogenation of 3nitrostyrene. Similar to the case of $0.03 \mathrm{Pt} / \mathrm{TiO}_{2}-\mathrm{SA}, \mathrm{Pt}$ atoms supported on $\mathrm{Al}_{2} \mathrm{O}_{3}$ remain stable after the hydrogenation reaction under such mild conditions (see Figure S15). In the case of reduced $\mathrm{Pt} / \mathrm{Al}_{2} \mathrm{O}_{3}$ samples, considerable conversion of 3-nitrostyrene can be observed and the reactivity increases with the reduction temperature, which corresponds to the higher percentage of $\mathrm{Pt}$ nanoparticles in the $0.2 \mathrm{Pt} / \mathrm{Al}_{2} \mathrm{O}_{3}-450 \mathrm{H}_{2}$ catalyst. Although the $\mathrm{Pt} / \mathrm{Al}_{2} \mathrm{O}_{3}$ catalysts are not chemoselective for 3 -aminostyrene ( $\sim 60 \%$ selectivity to 3 -aminostyrene on all the three $\mathrm{Pt} / \mathrm{Al}_{2} \mathrm{O}_{3}$ catalysts, see Figure $\mathrm{S} 16$ ), the ranking of the activity for the hydrogenation of 3-nitrostyrene is similar to $\mathrm{Pt} / \mathrm{TiO}_{2}$ catalysts, indicating that Pt clusters and nanoparticles show higher reactivity than Pt single atoms.

Because it has been reported in the literature that singly dispersed $\mathrm{Pt}$ atoms can be used for the hydrogenation of $\mathrm{C}=\mathrm{C}$ bonds, we have also tested the reactivity of $\mathrm{Pt} / \mathrm{Al}_{2} \mathrm{O}_{3}$ catalysts for the hydrogenation of styrene. As can be seen in Figure $6 \mathrm{~b}$, singly dispersed $\mathrm{Pt}$ atoms also show negligible activity toward the hydrogenation of $\mathrm{C}=\mathrm{C}$ bonds. The $\mathrm{Pt} / \mathrm{Al}_{2} \mathrm{O}_{3}$ catalysts with agglomerated Pt species show much higher activity and the activity increases with the percentage of Pt nanoparticles in the catalyst, indicating that $\mathrm{Pt}$ nanoparticles are more active than single $\mathrm{Pt}$ atoms and clusters for the hydrogenation of $\mathrm{C}=$ C bonds.

One may argue that the single-atom catalysts shown above are not reduced, although the single-atom Pt catalysts are also usually positively charged in most of the reported works. ${ }^{23,54,55}$ We have tried to reduce the $\mathrm{Pt}$ single atoms supported on $\mathrm{Al}_{2} \mathrm{O}_{3}$ by $\mathrm{NaBH}_{4}$ and aqueous $\mathrm{N}_{2} \mathrm{H}_{4}$ (see the Experimental Section for details). After such mild reduction treatment, the activity for the hydrogenation of styrene and 3-nitrostyrene remained in both cases unchanged as the pristine $\mathrm{Pt} / \mathrm{Al}_{2} \mathrm{O}_{3}-\mathrm{SA}$ sample.

From a mechanistic point of view, the hydrogenation of $-\mathrm{NO}_{2}$ and $\mathrm{C}=\mathrm{C}$ may follow different reaction mechanisms on metal catalysts. $^{40,56,57}$ It has been reported that the hydrogenation of $\mathrm{C}=\mathrm{C}$ on nanoparticulate $\mathrm{Pt}$ catalysts is a structure-insensitive reaction, while the hydrogenation of $-\mathrm{NO}_{2}$ is a structure-sensitive reaction. Nevertheless, our experimental results show that $\mathrm{Pt}$ nanoparticles are more active than Pt clusters and single Pt atoms for the two hydrogenation reactions. In other words, the above results indicate that singly dispersed $\mathrm{Pt}$ atoms supported on $\mathrm{TiO}_{2}$ and $\mathrm{Al}_{2} \mathrm{O}_{3}$ show much lower activity for the hydrogenation of $-\mathrm{NO}_{2}$ and $\mathrm{C}=\mathrm{C}$ groups.

Taking into account that residual $\mathrm{Cl}$ may be present in the $\mathrm{Pt} / \mathrm{TiO}_{2}$ and $\mathrm{Pt} / \mathrm{Al}_{2} \mathrm{O}_{3}$ catalysts when using $\mathrm{H}_{2} \mathrm{PtCl}_{6}$ as the $\mathrm{Pt}$ precursor, we have tried to measure the $\mathrm{Pt}-\mathrm{Cl}$ bonding interaction in $\mathrm{Pt} / \mathrm{Al}_{2} \mathrm{O}_{3}$ samples by XANES. ${ }^{58}$ As shown in Figure $\mathrm{S} 17$, the feature corresponding to the $\mathrm{Pt}-\mathrm{Cl}$ bond is not present in our samples. ${ }^{59}$ Furthermore, in order to exclude the influence of $\mathrm{Cl}$, we have prepared $\mathrm{Pt} / \mathrm{TiO}_{2}$ catalysts using platinum(II) acetylacetonate as the precursor by impregnating it on $\mathrm{TiO}_{2}$. When the sample is activated in air $\left(350^{\circ} \mathrm{C}\right.$ in air) for the decomposition of the acetylacetonate ligand bonded to $\mathrm{Pt}$, we can obtain a $\mathrm{Pt} / \mathrm{TiO}_{2}$ sample containing atomically dispersed Pt species (see Figures S18-S21). Further reduction treatment at $450{ }^{\circ} \mathrm{C}$ by $\mathrm{H}_{2}$ will lead to the agglomeration of the $\mathrm{Pt}$ atoms into $\mathrm{Pt}$ clusters or nanoparticles, showing a similar evolution behavior as observed when using $\mathrm{H}_{2} \mathrm{PtCl}_{6}$ as the precursor. When increasing the Pt loading from 0.04 to $0.5 \mathrm{wt}$ $\%$, the size of Pt particles also increases from 0.5 to $\sim 1 \mathrm{~nm}$. It should be noted that the size of $\mathrm{Pt}$ species is smaller in the $\mathrm{Pt} /$ 

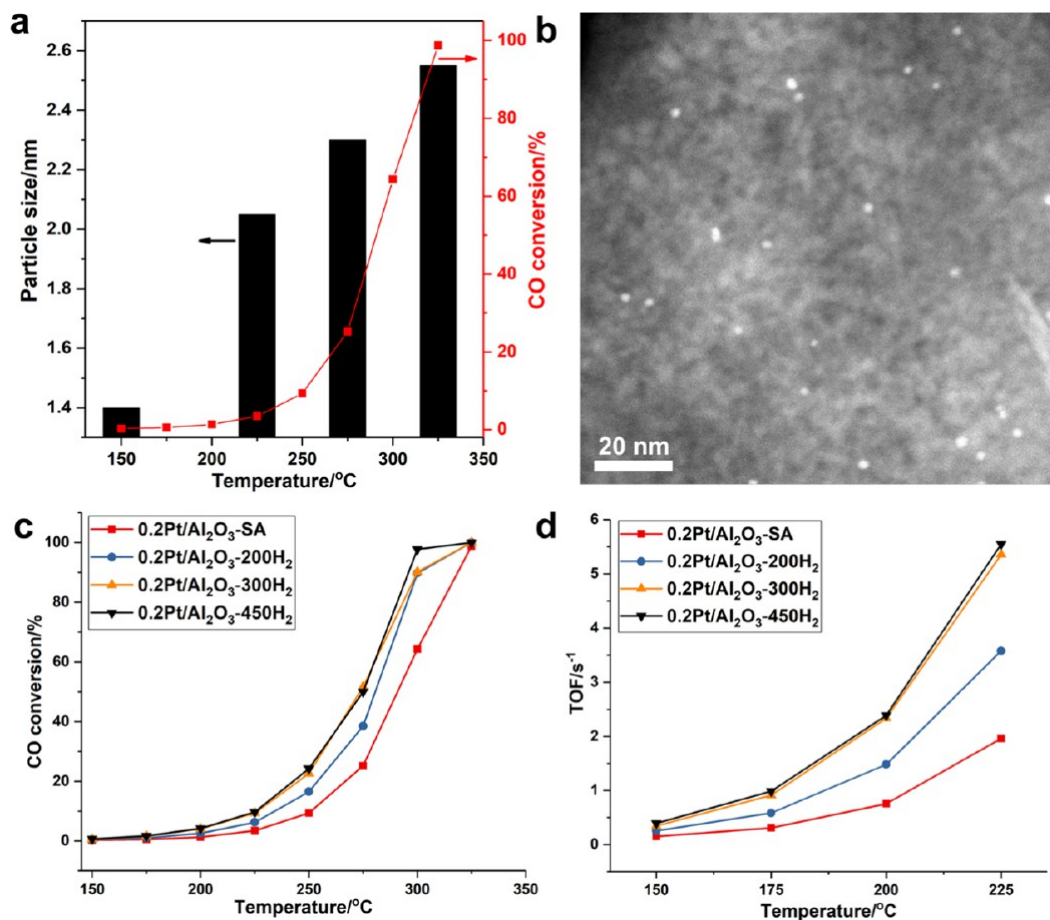

Figure 7. Different types of $\mathrm{Pt}$ species supported on $\mathrm{Al}_{2} \mathrm{O}_{3}$ for $\mathrm{CO}$ oxidation. (a) Catalytic result of the $0.2 \mathrm{Pt} / \mathrm{Al}_{2} \mathrm{O}_{3}-\mathrm{SA}$ sample for CO oxidation and the evolution of $\mathrm{Pt}$ single atoms to Pt nanoparticles under $\mathrm{CO}$ oxidation reaction conditions. The average sizes of Pt nanoparticles at different reaction temperatures are shown in this figure. (b) Typical HAADF-STEM image of the $0.2 \mathrm{Pt} / \mathrm{Al}_{2} \mathrm{O}_{3}-\mathrm{SA}$ sample after the CO oxidation reaction, showing the presence of $\mathrm{Pt}$ nanoparticles in the used catalyst. (c) Comparison of the catalytic performance of $\mathrm{Pt} / \mathrm{Al}_{2} \mathrm{O}_{3}$ catalysts with different sizes, ranging from single atoms to clusters to nanoparticles. (d) TOF values of different $\mathrm{Pt} / \mathrm{Al}_{2} \mathrm{O}_{3}$ catalysts in the low-temperature range $\left(150-225{ }^{\circ} \mathrm{C}\right.$ ) for the $\mathrm{CO}$ oxidation reaction. The TOF in this figure was calculated based on the total Pt amount in all the $\mathrm{Pt} / \mathrm{Al}_{2} \mathrm{O}_{3}$ samples.

$\mathrm{TiO}_{2}$ samples prepared with $\mathrm{Pt}(\mathrm{acac})_{2}$ than those prepared with $\mathrm{H}_{2} \mathrm{PtCl}_{6}$.

We have tested the catalytic performance of these $\mathrm{Cl}$-free $\mathrm{Pt} / \mathrm{TiO}_{2}$ samples for the hydrogenation of 3-nitrostyrene. As shown in Figure S22, the initial TOF increases with the $\mathrm{Pt}$ loading, which means the TOF also increases with the size of $\mathrm{Pt}$ particles supported on $\mathrm{TiO}_{2}$. This trend is consistent with the results obtained with $\mathrm{Pt} / \mathrm{TiO}_{2}$ samples prepared with $\mathrm{H}_{2} \mathrm{PtCl}_{6}$, among which the Pt particles of $\sim 1 \mathrm{~nm}$ show the highest activity. Notably, the absolute TOF values obtained with $\mathrm{Pt} / \mathrm{TiO}_{2}$ catalysts prepared with $\mathrm{Pt}(\mathrm{acac})_{2}$ are lower than the $\mathrm{Pt} / \mathrm{TiO}_{2}$ samples prepared with $\mathrm{H}_{2} \mathrm{PtCl}_{6}$, indicating that the $\mathrm{Pt}$ precursor indeed has influence on the catalytic performance of supported Pt catalysts.

One may argue that the reduction treatment used in the preparation procedure may influence the surface properties of the oxide support. In order to exclude the reduction treatment on the support, we have prepared a $\mathrm{PtNP} / \mathrm{TiO}_{2}$ catalyst by loading colloid $\mathrm{Pt}$ nanoparticles $(0.2 \mathrm{wt} \% \mathrm{of} \mathrm{Pt})$ on the surface of $\mathrm{TiO}_{2}$. In such a way, Pt nanoparticles can be generated on $\mathrm{TiO}_{2}$ without reduction treatment. Furthermore, a calcination treatment at $450{ }^{\circ} \mathrm{C}$ in air was carried out with the $\mathrm{PtNP} / \mathrm{TiO}_{2}$ sample to remain consistent with the preparation of the $0.03 \mathrm{Pt} / \mathrm{TiO}_{2}-\mathrm{SA}$ sample (see Figures S23 and S24).

We have tested the $\mathrm{PtNP} / \mathrm{TiO}_{2}$ samples for the hydrogenation of 3-nitrostyrene under the same conditions as used in the article. As shown in Figures S25 and S26, both PtNP/ $\mathrm{TiO}_{2}$-air and $\mathrm{PtNP} / \mathrm{TiO}_{2}-450 \mathrm{H}_{2}$ are active, though $\mathrm{PtNP} /$ $\mathrm{TiO}_{2}-450 \mathrm{H}_{2}$ gives a slightly higher initial TOF. Notably, though the $\mathrm{PtNP} / \mathrm{TiO}_{2}$-air sample has been calcined in air, as for the $\mathrm{Pt} / \mathrm{TiO}_{2}$-SA sample, its activity is much higher than the $\mathrm{Pt} / \mathrm{TiO}_{2}-\mathrm{SA}$ sample containing singly dispersed $\mathrm{Pt}$ atoms.
These results confirm the vital role of agglomerated Pt species for the hydrogenation reaction. Importantly, the selectivity to 3 -aminostyrene is much higher with the reduced $\mathrm{PtNP} / \mathrm{TiO}_{2}$ $450 \mathrm{H}_{2}$ sample, which should be related to the formation of $\mathrm{TiO}_{2-x}$ overlayers on $\mathrm{Pt}$ nanoparticles because of strong metal-support interaction. ${ }^{40}$

2.2. CO Oxidation Reaction with Pt Single Atoms, Clusters, and Nanoparticles. CO oxidation is another important model reaction to study the structure-reactivity correlations of supported metal catalysts. It has been reported in the literature that $\mathrm{Pt}$ single atoms supported on $\mathrm{Al}_{2} \mathrm{O}_{3}$ are active for $\mathrm{CO}$ oxidation. In this work, we have tested the catalytic activity of $\mathrm{Pt}$ single atoms supported on $\mathrm{Al}_{2} \mathrm{O}_{3}$ and followed the evolution of $\mathrm{Pt}$ single atoms during the $\mathrm{CO}$ oxidation reaction. The presence of singly dispersed $\mathrm{Pt}$ atoms is confirmed by low-temperature IR bands at $2120-2150 \mathrm{~cm}^{-1}$ (see Figure S27), which correspond to $\mathrm{CO}$ adsorbed on cationic Pt atoms. ${ }^{16,17}$ As shown in Figures $7 \mathrm{~b}$ and S28, it is found that Pt single atoms agglomerate into Pt nanoparticles under reaction conditions. Moreover, the size of the in situ formed $\mathrm{Pt}$ nanoparticles also increases with the reaction temperature from 150 to $325{ }^{\circ} \mathrm{C}$, indicating that $\mathrm{Pt}$ species suffer dynamic structural transformation under $\mathrm{CO}$ oxidation conditions (see Figures 7a and S29-S32).

The structural transformation of $\mathrm{Pt}$ single atoms into $\mathrm{Pt}$ nanoparticles has also been performed, followed by in situ CO IR spectroscopy. As displayed in Figure 8, the formation of $\mathrm{Pt}$ nanoparticles after the $\mathrm{CO}+\mathrm{O}_{2}$ reaction at $225{ }^{\circ} \mathrm{C}$ can be identified by the $\mathrm{CO}$ adsorption bands at $2075-2050 \mathrm{~cm}^{-1}$. The CO IR band at 2075 and $2050 \mathrm{~cm}^{-1}$ corresponds to CO adsorbed on terrace and corner $\mathrm{Pt}$ sites, respectively. Interestingly, after the $\mathrm{CO}$ oxidation reaction at higher 


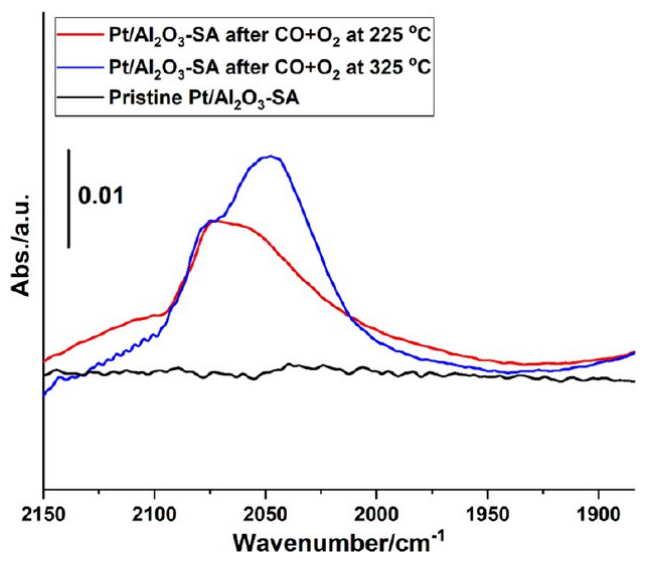

Figure 8. Evolution of Pt single atoms under $\mathrm{CO}$ oxidation reaction conditions, followed by in situ CO IR spectroscopy. The pristine $0.2 \mathrm{Pt} / \mathrm{Al}_{2} \mathrm{O}_{3}$-SA sample containing singly dispersed $\mathrm{Pt}$ atoms shows negligible absorption of $\mathrm{CO}$ at room temperature because of the weak adsorption of $\mathrm{CO}$ on cationic $\mathrm{Pt}$ atoms. After the $\mathrm{CO}$ oxidation reaction at 225 and $320{ }^{\circ} \mathrm{C}$, typical $\mathrm{CO}$ adsorption bands on $\mathrm{Pt}$ nanoparticles can be observed, indicating the agglomeration of $\mathrm{Pt}$ single atoms into nanoparticles under reaction conditions, which is consistent with the images obtained by electron microscopy.

temperature $\left(325{ }^{\circ} \mathrm{C}\right)$, the contribution of $\mathrm{CO}$ adsorbed on corner Pt sites increases, implying that a surface reconstruction or disintegration of $\mathrm{Pt}$ nanoparticles into smaller particles occurs at high reaction temperature, which is consistent with our previous study on $\mathrm{Pt}$ particles confined in zeolite. ${ }^{34}$ The structural transformation behavior of $\mathrm{Pt}$ nanoparticles also indicates that the $\mathrm{CO}$ oxidation reaction is a structure-sensitive reaction and the active sites could be varied at different working temperatures.

The sintering of single $\mathrm{Pt}$ atoms into $\mathrm{Pt}$ clusters and nanoparticles is confirmed by in situ XAS. As shown in Figure 9a, the white line intensity of Pt-edge XANES decreased gradually in the $\mathrm{CO}+\mathrm{O}_{2}$ atmosphere when increasing the reaction temperature from 25 to $225{ }^{\circ} \mathrm{C}$, indicating the reduction of $\mathrm{Pt}$ single atoms under reaction conditions. Furthermore, according to the $|\mathrm{FT}|$ of Pt-edge EXAFS spectra (see Figure 9b and Table 2), a new contribution at $2.7 \AA$ can be associated with $\mathrm{Pt}-\mathrm{Pt}$ bonding, suggesting the transformation of singly dispersed $\mathrm{Pt}$ species into agglomerated $\mathrm{Pt}$ particles, which has also been observed in a very recent publication. ${ }^{60}$ In order to compare the reactivity of Pt single atoms, clusters, and nanoparticles, we have tested the $\mathrm{Pt} / \mathrm{Al}_{2} \mathrm{O}_{3}$ catalysts for $\mathrm{CO}$ oxidation on different types of $\mathrm{Pt}$ species generated by controlled reduction treatment. As shown in Figure $7 \mathrm{c}, \mathrm{d}$, both $\mathrm{Pt}$ clusters and $\mathrm{Pt}$ nanoparticles show significantly higher TOFs (normalized to the amount of $\mathrm{Pt}$ atoms in the catalyst) than $\mathrm{Pt}$ single atoms. $0.2 \mathrm{Pt} / \mathrm{Al}_{2} \mathrm{O}_{3}-300 \mathrm{H}_{2}$ and $0.2 \mathrm{Pt} / \mathrm{Al}_{2} \mathrm{O}_{3}-450 \mathrm{H}_{2}$ samples show similar activity, while $0.2 \mathrm{Pt} / \mathrm{Al}_{2} \mathrm{O}_{3}-200 \mathrm{H}_{2}$ shows intermediate activity between these two samples. It should be mentioned that the TOF values shown in Figure $7 \mathrm{~d}$ are calculated based on all the Pt species in the catalyst. If we calculate the TOF based on surface-exposed atoms, then Pt clusters and nanoparticles may show even higher TOF, while the TOF for Pt single atoms will remain unchanged. On the basis of the catalytic results shown in Figure 7 and the size distribution of $\mathrm{Pt}$ species in various $\mathrm{Pt} /$ $\mathrm{Al}_{2} \mathrm{O}_{3}$ samples, it can be concluded that the $0.2 \mathrm{Pt} / \mathrm{Al}_{2} \mathrm{O}_{3}-\mathrm{SA}$ sample with a higher fraction of single $\mathrm{Pt}$ atoms shows lower activity for $\mathrm{CO}$ oxidation than $\mathrm{Pt}$ nanoparticles and clusters supported on $\mathrm{Al}_{2} \mathrm{O}_{3}$.

We have also observed that the average size of $\mathrm{Pt}$ nanoparticles in $\mathrm{Pt} / \mathrm{Al}_{2} \mathrm{O}_{3}$-SA after the $\mathrm{CO}$ oxidation reaction is larger than those in the $0.2 \mathrm{Pt} / \mathrm{Al}_{2} \mathrm{O}_{3}-300 \mathrm{H}_{2}$ and $0.2 \mathrm{Pt} /$ $\mathrm{Al}_{2} \mathrm{O}_{3}-450 \mathrm{H}_{2}$ samples after being used for the $\mathrm{CO}+\mathrm{O}_{2}$ reaction (see Figures S33-S36). As discussed above, Pt single atoms are not stable in the $\mathrm{CO}+\mathrm{O}_{2}$ atmosphere and they agglomerate to $\mathrm{Pt}$ nanoparticles probably through an Ostwald ripening mechanism, in which single $\mathrm{Pt}$ atoms migrate to the $\mathrm{Pt}$ clusters or nanoparticles to form larger particles. In the case of $0.2 \mathrm{Pt} / \mathrm{Al}_{2} \mathrm{O}_{3}-300 \mathrm{H}_{2}$ and $0.2 \mathrm{Pt} / \mathrm{Al}_{2} \mathrm{O}_{3}-450 \mathrm{H}_{2}$ samples, $\mathrm{Pt}$ clusters or small nanoparticles are stabilized by the $\mathrm{Al}_{2} \mathrm{O}_{3}$ support and the Ostwald ripening process under $\mathrm{CO}$ oxidation reaction conditions is not as significant as in the $0.2 \mathrm{Pt} / \mathrm{Al}_{2} \mathrm{O}_{3}$ SA sample. This structural transformation behavior can be related to the stability of different $\mathrm{Pt}$ species under $\mathrm{CO}$ oxidation reaction conditions and to the fact that Ostwald ripening tends to occur between particles of different sizes. $^{61-63}$

Catalytic Behavior of Pt Single Atoms Supported on $\mathrm{TiO}_{2}$ and $\mathrm{CeO}_{2}$ for $\mathrm{CO}$ Oxidation. In the case of $0.03 \mathrm{Pt} /$ $\mathrm{TiO}_{2}$-SA, a similar agglomeration behavior from single atoms to nanoparticles is observed during the $\mathrm{CO}$ oxidation test (see Figures 10a,b and S37). Then, we have compared the activity of $\mathrm{Pt}$ clusters and nanoparticles with that of single Pt atoms. As shown in Figure 10c, Pt clusters show the highest TOF value, followed by $\mathrm{Pt}$ nanoparticles. Similar to the situation with
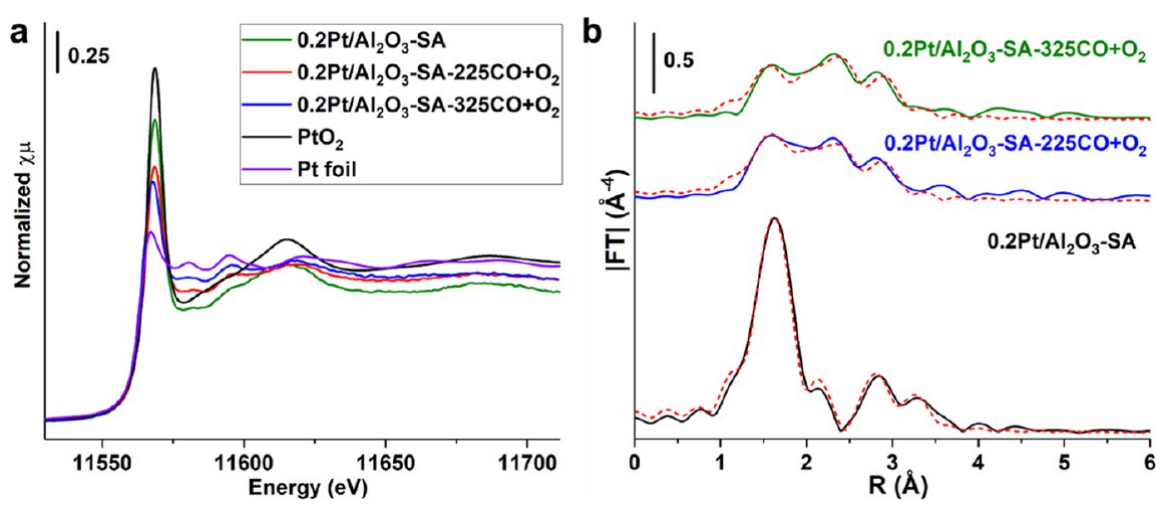

Figure 9. Evolution of Pt single atoms supported on $\mathrm{Al}_{2} \mathrm{O}_{3}$ under $\mathrm{CO}+\mathrm{O}_{2}$ reaction conditions, followed by in situ XAS. (a) XANES spectra and (b) EXAFS spectra (not phase-corrected) of the pristine $0.2 \mathrm{Pt} / \mathrm{Al}_{2} \mathrm{O}_{3}-\mathrm{SA}$ sample and the corresponding sample after the $\mathrm{CO}+\mathrm{O}_{2}$ reaction at 225 and $325{ }^{\circ} \mathrm{C}$, respectively. The fit curves of the EXAFS spectra are presented as dashed red curves in (b). 
Table 2. Fit Results of the Pristine $\mathrm{Pt} / \mathrm{Al}_{2} \mathrm{O}_{3}$-SA Sample and the Sample after in Situ XAS Experiments under $\mathrm{CO}+\mathrm{O}_{2}$ Reaction Conditions ${ }^{a}$

\begin{tabular}{|c|c|c|c|c|c|c|c|c|c|}
\hline \multirow[b]{2}{*}{ sample } & \multicolumn{3}{|c|}{$\mathrm{Pt}-\mathrm{O}$} & \multicolumn{3}{|c|}{$\mathrm{Pt}-\mathrm{Pt}$} & \multicolumn{3}{|c|}{$\mathrm{Pt}-\mathrm{Al}$} \\
\hline & $\mathrm{CN}_{\mathrm{Pt}-\mathrm{O}}$ & $R(\AA)$ & $\sigma^{2}\left(\AA^{2}\right)$ & $\mathrm{CN}_{\mathrm{t}}$ & $R_{\mathrm{t}}(\AA)$ & $\sigma_{\mathrm{t}}^{2}\left(\AA^{2}\right)$ & $\mathrm{CN}_{\mathrm{t}}$ & $R(\AA)$ & $\sigma_{\mathrm{t}}^{2}\left(\AA^{2}\right)$ \\
\hline $0.2 \mathrm{Pt} / \mathrm{Al}_{2} \mathrm{O}_{3}-\mathrm{SA}^{b}$ & $6.2 \pm 0.9$ & $2.00 \pm 0.01$ & $0.003 \pm 0.002$ & & & & $3 \pm 2$ & $2.92 \pm 0.05$ & 0.01 \\
\hline $0.2 \mathrm{Pt} / \mathrm{Al}_{2} \mathrm{O}_{3}-\mathrm{SA}-225 \mathrm{CO}+\mathrm{O}_{2}{ }^{c}$ & $2.4 \pm 0.8$ & $1.99 \pm 0.02$ & $0.008 \pm 0.006$ & $8 \pm 3$ & $2.77 \pm 0.01$ & $0.01 \pm 0.003$ & & & \\
\hline $0.2 \mathrm{Pt} / \mathrm{Al}_{2} \mathrm{O}_{3}-\mathrm{SA}-325 \mathrm{CO}+\mathrm{O}_{2}{ }^{c}$ & $1.5 \pm 0.7$ & $1.96 \pm 0.02$ & $0.005 \pm 0.006$ & $9 \pm 3$ & $2.76 \pm 0.01$ & $0.01 \pm 0.003$ & & & \\
\hline
\end{tabular}

${ }^{a} \Delta E_{0}=9, R_{\text {factor }}=0.7$. To decrease the number of parameters, the Debye-Waller $\left(\sigma^{2}\right)$ was kept free but the same for all paths with exception of the second shell contribution in the $\mathrm{Pt} / \mathrm{Al}_{2} \mathrm{O}_{3}$ samples measured directly. In this case, it was fixed to 0.01 . $^{b}$ The sample was directly measured by XAS without any treatment. ${ }^{c}$ The sample was treated under $\mathrm{CO}+\mathrm{O}_{2}$ conditions at a given temperature before the XAS measurement.
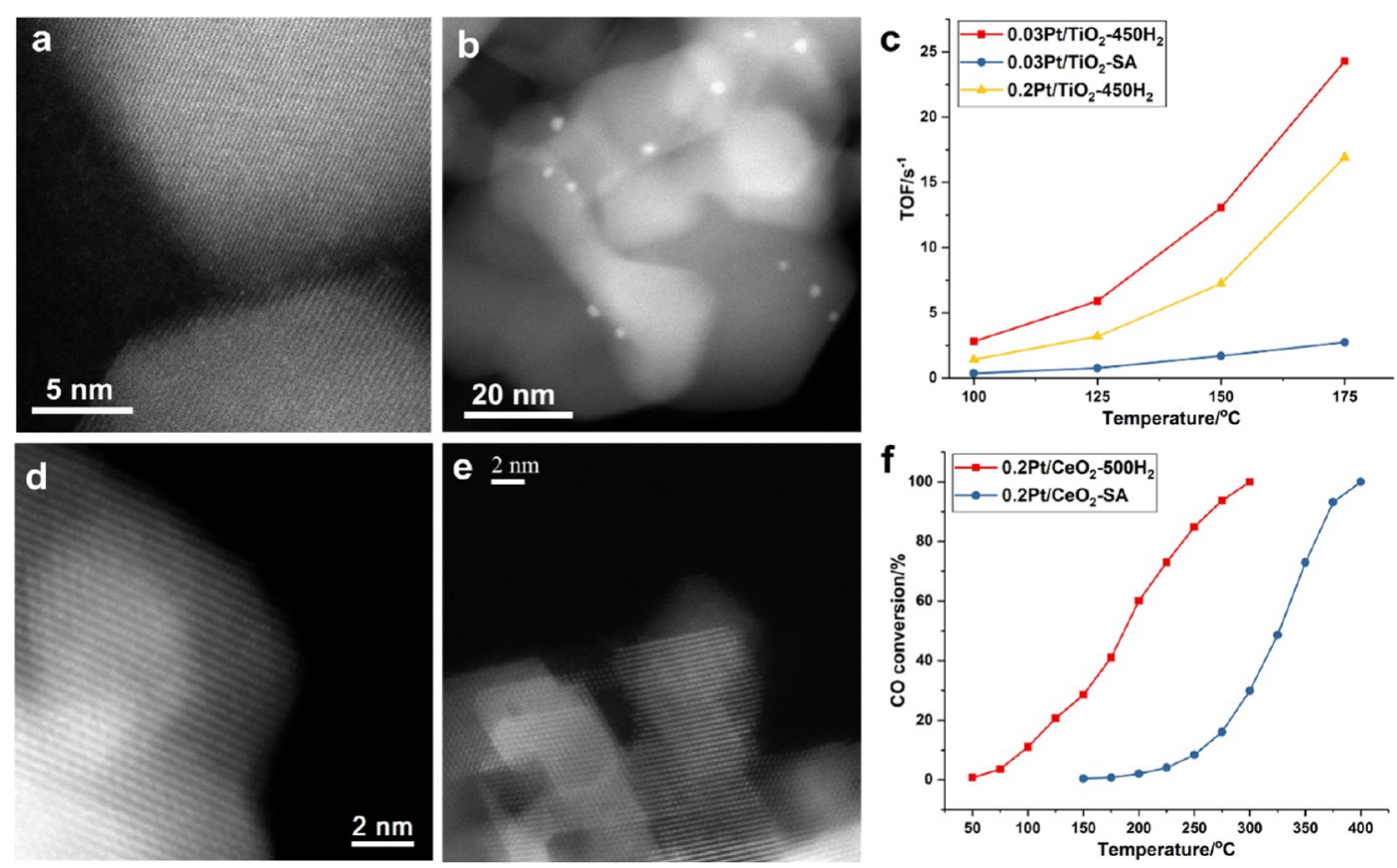

Figure 10. Size effect of $\mathrm{Pt}$ species supported on $\mathrm{TiO}_{2}$ and $\mathrm{CeO}_{2}$ for $\mathrm{CO}$ oxidation. (a) HR STEM image of fresh 0.03Pt/TiO ${ }_{2}-\mathrm{SA}$ sample, showing the presence of single $\mathrm{Pt}$ atoms dispersed on $\mathrm{TiO}_{2}$. (b) STEM image of the $0.03 \mathrm{Pt} / \mathrm{TiO}_{2}-\mathrm{SA}$ catalyst after the $\mathrm{CO}$ oxidation reaction, showing the transformation of singly dispersed $\mathrm{Pt}$ atoms into Pt nanoparticles under reaction conditions. (c) Comparison of the activity of Pt single atoms, clusters, and nanoparticles for low-temperature $\mathrm{CO}$ oxidation. (d) HR STEM image of fresh $0.2 \mathrm{Pt} / \mathrm{CeO}_{2}-\mathrm{SA}$ sample. Because of the low contrast between Pt single atoms and $\mathrm{CeO}_{2}$, it is difficult to visualize Pt single atoms. Nevertheless, neither Pt nanoparticles nor clusters are observed in this

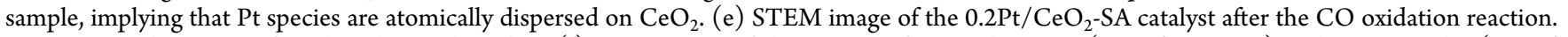
$\mathrm{Pt}$ nanoparticles are not found in the used catalyst. (f) Comparison of the activity of Pt single atoms $\left(0.2 \mathrm{Pt} / \mathrm{CeO}_{2}-\mathrm{SA}\right)$ and nanoparticles $(0.2 \mathrm{Pt} /$ $\mathrm{CeO}_{2}-500 \mathrm{H}_{2}$ ) for $\mathrm{CO}$ oxidation.

$0.2 \mathrm{Pt} / \mathrm{Al}_{2} \mathrm{O}_{3}$ samples, $\mathrm{Pt}$ single atoms supported on $\mathrm{TiO}_{2}$ exhibit the lowest TOF. It should be noted that the variation tendency of $\mathrm{CO}$ oxidation activity versus $\mathrm{Pt}$ particle size is different on $\mathrm{Al}_{2} \mathrm{O}_{3}$ and $\mathrm{TiO}_{2}$, implying that the reactivity of different types of metal entities may depend on the support. In the case of $\mathrm{Pt} / \mathrm{CeO}_{2}$ containing single $\mathrm{Pt}$ atoms $\left(0.2 \mathrm{Pt} / \mathrm{CeO}_{2}\right.$ SA, see Figure S38), the activity is quite low, which is in line with the reported work. ${ }^{16}$ After the $\mathrm{CO}$ oxidation reaction with $0.2 \mathrm{Pt} / \mathrm{CeO}_{2}-\mathrm{SA}$, the agglomeration of $\mathrm{Pt}$ atoms into clusters or nanoparticles has not been observed (see Figures 10d,e and S39), implying that $\mathrm{Pt}$ atoms are stabilized by $\mathrm{CeO}_{2}$ under reaction conditions. The behavior of $\mathrm{Pt}$ atoms supported on $\mathrm{CeO}_{2}$ is dramatically different from that of $\mathrm{Pt}$ atoms supported on $\mathrm{Al}_{2} \mathrm{O}_{3}$ and $\mathrm{TiO}_{2}$, suggesting that the evolution behavior of $\mathrm{Pt}$ single atoms also depends on the interaction between $\mathrm{Pt}$ and the support. In any case, while single $\mathrm{Pt}$ atoms are stable on $\mathrm{CeO}_{2}$, they are not active for the $\mathrm{CO}$ oxidation reaction. Afterward, as done before, the $0.2 \mathrm{Pt} / \mathrm{CeO}_{2}-\mathrm{SA}$ sample was reduced by $\mathrm{H}_{2}$ at $500{ }^{\circ} \mathrm{C}$ to generate $\mathrm{Pt}$ nanoparticles of $1-2$ nm on $\mathrm{CeO}_{2}$ (see Figure S40). As shown in Figure 10f, the $0.2 \mathrm{Pt} / \mathrm{CeO}_{2}-500 \mathrm{H}_{2}$ sample exhibits much higher activity than $0.2 \mathrm{Pt} / \mathrm{CeO}_{2}-\mathrm{SA}$, which is consistent with a very recent publication. $^{64}$ Those $\mathrm{Pt}$ nanoparticles of $1-2 \mathrm{~nm}$ in the $0.2 \mathrm{Pt} / \mathrm{CeO}_{2}-500 \mathrm{H}_{2}$ sample remained stable after the $\mathrm{CO}+\mathrm{O}_{2}$ reaction (see Figure S41). The above results suggest that for low-temperature $\mathrm{CO}$ oxidation reaction, $\mathrm{Pt}$ clusters and nanoparticles are more active than $\mathrm{Pt}$ single atoms on $\mathrm{Al}_{2} \mathrm{O}_{3}$, $\mathrm{TiO}_{2}$, and $\mathrm{CeO}_{2}$. Furthermore, the reactivity of Pt clusters and nanoparticles and the evolution behavior are strongly relevant to the support, implying the importance of considering the role of the support when discussing the catalytic behavior of heterogeneous single-atom catalysts. ${ }^{65,66}$

The higher capability for $\mathrm{O}_{2}$ activation on the $0.2 \mathrm{Pt} / \mathrm{CeO}_{2}-$ $500 \mathrm{H}_{2}$ sample is confirmed by in situ IR experiments. As presented in Figure S42, peroxide species can only be detected on the $0.2 \mathrm{Pt} / \mathrm{CeO}_{2}-500 \mathrm{H}_{2}$ sample containing $\mathrm{Pt}$ nanoparticles but not on the $0.2 \mathrm{Pt} / \mathrm{CeO}_{2}$-SA sample. The activation of $\mathrm{O}_{2}$ on the metal/ceria catalyst has been proposed to occur at the 

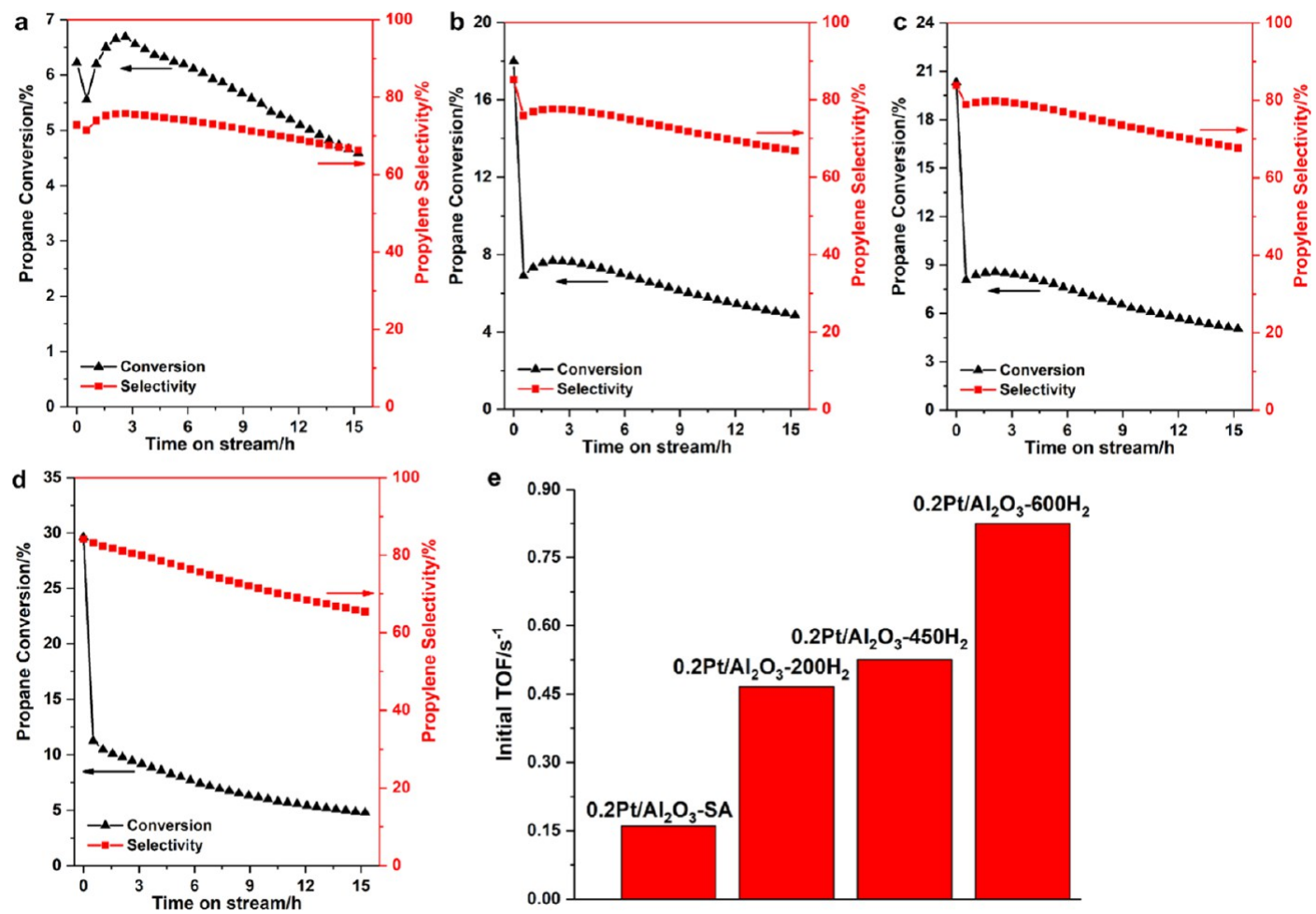

Figure 11. Catalytic performance of different $\mathrm{Pt} / \mathrm{Al}_{2} \mathrm{O}_{3}$ catalysts for the propane dehydrogenation reaction at $600{ }^{\circ} \mathrm{C}$. (a) $0.2 \mathrm{Pt} / \mathrm{Al}_{2} \mathrm{O}_{3}-\mathrm{SA},(\mathrm{b})$ $0.2 \mathrm{Pt} / \mathrm{Al}_{2} \mathrm{O}_{3}-200 \mathrm{H}_{2}$, (c) $0.2 \mathrm{Pt} / \mathrm{Al}_{2} \mathrm{O}_{3}-450 \mathrm{H}_{2}$, and (d) $0.2 \mathrm{Pt} / \mathrm{Al}_{2} \mathrm{O}_{3}-600 \mathrm{H}_{2}$. The TOF values shown in (e) are calculated based on all $\mathrm{Pt}$ atoms in the catalyst. Reaction conditions: $140 \mathrm{mg}$ of solid catalyst, mixture of propane and $\mathrm{N}_{2}$ as the feed gas $\left(5 \mathrm{~mL} / \mathrm{min}\right.$ of propane and $16 \mathrm{~mL} / \mathrm{min}$ of $\left.\mathrm{N}_{2}\right)$ at $600{ }^{\circ} \mathrm{C}$.

interface between metal nanoparticles and ceria, with the participation of oxygen vacancies, which is verified by the presence of $\mathrm{Ce}^{3+}$ in the $\mathrm{X}$-ray photoelectron spectroscopy spectrum of the reduced $0.2 \mathrm{Pt} / \mathrm{CeO}_{2}-500 \mathrm{H}_{2}$ sample (see Figure S43). ${ }^{67,68}$ The IR results imply that $\mathrm{O}_{2}$ activation is facilitated at the interface between $\mathrm{Pt}$ nanoparticles and $\mathrm{CeO}_{2}$ rather than between $\mathrm{Pt}$ single atoms and $\mathrm{CeO}_{2}$, which can explain why the $0.2 \mathrm{Pt} / \mathrm{CeO}_{2}-500 \mathrm{H}_{2}$ sample is more active for $\mathrm{CO}$ oxidation. It has been shown by both experimental and theoretical studies that $\mathrm{Cu}$ nanoparticles are more active than $\mathrm{Cu}$ single atoms or clusters for $\mathrm{O}_{2}$ activation. ${ }^{69,70}$ Although the metal element $(\mathrm{Cu})$ studied in the above reports is different, taking into account the catalytic results presented here, one could make the hypothesis that if multiple metal atoms are required for $\mathrm{O}_{2}$ activation, it may also be applied to Pt. Nevertheless, the adsorption of $\mathrm{CO}$ behavior on $\mathrm{Pt}$ species could also be related to the particle size. ${ }^{71}$

In summary, the results presented above in this work indicate that single $\mathrm{Pt}$ atoms may evolve into Pt clusters or nanoparticles under $\mathrm{CO}$ oxidation reaction conditions if the interaction between $\mathrm{Pt}$ atoms and the support is not strong enough. Moreover, regardless of the reducibility of the support, the agglomerated $\mathrm{Pt}$ species (clusters or nanoparticles) are more active than the $\mathrm{Pt}$ single atoms on $\mathrm{Al}_{2} \mathrm{O}_{3}, \mathrm{TiO}_{2}$, and $\mathrm{CeO}_{2}$. It should be noted that the active sites and the kinetically relevant steps on support Pt catalysts may vary with the support and the reaction conditions. ${ }^{72-74}$ Considering the complexity of the reaction mechanism for the $\mathrm{CO}$ oxidation reaction and its dependence on the size and the support material, the reasons that cause the different catalytic behavior of single $\mathrm{Pt}$ atoms and the corresponding agglomerates are not in the scope of this study, which requires more systematic investigations in the future.

2.3. Propane Dehydrogenation with Pt Single Atoms, Clusters, and Nanoparticles. It has been reported that propane dehydrogenation to propylene is a structure-sensitive reaction, in which the activity on $\mathrm{Pt}$ nanoparticles increases when decreasing the particle size in the range of $1-9 \mathrm{~nm}^{75}$ Recently, Xiong et al. have reported the application of singleatom $\mathrm{Pt} / \mathrm{CeO}_{2}$ and $\mathrm{Pt}-\mathrm{Sn} / \mathrm{CeO}_{2}$ catalysts for the propane dehydrogenation reaction, and it has been found that singly dispersed $\mathrm{Pt}$ atoms can undergo agglomeration into $\mathrm{Pt}$ or $\mathrm{PtSn}$ clusters under the reaction conditions. ${ }^{76}$ It is hence not clear how Pt single atoms perform when compared to Pt clusters and nanoparticles for the propane dehydrogenation reaction.

Herein, the reactivity of different types of $\mathrm{Pt}$ species supported on $\mathrm{Al}_{2} \mathrm{O}_{3}$ has also been tested. As shown in Figure 11 , the $0.2 \mathrm{Pt} / \mathrm{Al}_{2} \mathrm{O}_{3}-\mathrm{SA}$ sample is initially active for the catalytic dehydrogenation of propane to propylene, although the activity is low. However, a drop of activity is observed in the starting stage, and then the propane conversion increases again. These changes on reactivity imply that $\mathrm{Pt}$ species may undergo structural transformation under reaction conditions. Indeed, we have measured the used $0.2 \mathrm{Pt} / \mathrm{Al}_{2} \mathrm{O}_{3}$-SA sample after the propane dehydrogenation reaction, and the formation of a large fraction of $\mathrm{Pt}$ nanoparticles is confirmed by electron microscopy (see Figure S44). Furthermore, the catalytic performance of $0.2 \mathrm{Pt} / \mathrm{Al}_{2} \mathrm{O}_{3}-200 \mathrm{H}_{2}$ and $0.2 \mathrm{Pt} / \mathrm{Al}_{2} \mathrm{O}_{3}-450 \mathrm{H}_{2}$ for the propane dehydrogenation reaction has also been measured, and as can be seen in Figure 11, the $\mathrm{Pt} / \mathrm{Al}_{2} \mathrm{O}_{3}$ catalysts that contain $\mathrm{Pt}$ clusters and nanoparticles in the starting catalysts are initially more active than Pt single atoms. Interestingly, a decrease in activity and a subsequent activity 
recovery have also been observed with both $0.2 \mathrm{Pt} / \mathrm{Al}_{2} \mathrm{O}_{3}$ $200 \mathrm{H}_{2}$ and $0.2 \mathrm{Pt} / \mathrm{Al}_{2} \mathrm{O}_{3}-450 \mathrm{H}_{2}$. According to the STEM images of the used catalysts, the particle size of $\mathrm{Pt}$ species increases slightly compared to that of the corresponding pristine $0.2 \mathrm{Pt} / \mathrm{Al}_{2} \mathrm{O}_{3}-200 \mathrm{H}_{2}$ and $0.2 \mathrm{Pt} / \mathrm{Al}_{2} \mathrm{O}_{3}-450 \mathrm{H}_{2}$ samples (see Figures $\mathrm{S} 45$ and S46), suggesting a slight sintering of $\mathrm{Pt}$ species in these two catalysts during the propane dehydrogenation reaction. Therefore, it can be speculated that $\mathrm{Pt}$ nanoparticles with larger size than those in the $0.2 \mathrm{Pt} / \mathrm{Al}_{2} \mathrm{O}_{3}$ $450 \mathrm{H}_{2}$ sample may be more active. Following that hypothesis, $0.2 \mathrm{Pt} / \mathrm{Al}_{2} \mathrm{O}_{3}-\mathrm{SA}$ was reduced by $\mathrm{H}_{2}$ at $600{ }^{\circ} \mathrm{C}$ to form a $0.2 \mathrm{Pt} /$ $\mathrm{Al}_{2} \mathrm{O}_{3}-600 \mathrm{H}_{2}$ sample, in which a larger amount of Pt clusters and nanoparticles are formed compared to the $0.2 \mathrm{Pt} / \mathrm{Al}_{2} \mathrm{O}_{3}$ $200 \mathrm{H}_{2}$ and $0.2 \mathrm{Pt} / \mathrm{Al}_{2} \mathrm{O}_{3}-450 \mathrm{H}_{2}$ samples (see Figures $\mathrm{S} 47$ and S48). The catalytic results shown in Figure 11 clearly indicate that a higher percentage of Pt clusters and nanoparticles of $\sim 1$ $\mathrm{nm}$ can give higher activity for the propane dehydrogenation reaction and the propane conversion keeps decreasing with time on stream. On the basis of the above results, it can be concluded that $\mathrm{Pt}$ single atoms supported on $\mathrm{Al}_{2} \mathrm{O}_{3}$ are active but not stable for the propane dehydrogenation reaction, probably because of the sintering of single atoms to clusters and nanoparticles in the reductive atmosphere, while $\mathrm{Pt}$ clusters and nanoparticles are more active than Pt single atoms.

2.4. Photocatalytic $\mathrm{H}_{2}$ Evolution with $\mathrm{Pt}$ Single Atoms, Clusters, and Nanoparticles. In the above examples, conventional heterogeneous catalysis involving activation of small molecules was employed to study the catalytic behavior of different types of $\mathrm{Pt}$ species. $\mathrm{Pt}$ is also widely used for photocatalysis, in which Pt is usually thought to serve as the cocatalyst. The photogenerated electrons in the semiconductors will transfer to Pt sites, which catalyze the half reaction between protons and electrons to form $\mathrm{H}_{2} \cdot{ }^{77}$ It has been reported in the literature that the size of $\mathrm{Pt}$ cocatalysts has significant influence on the photocatalytic reactivity because of their size-dependent electronic structures. ${ }^{78,79}$ Recently, it has been reported that single-site-based metal catalysts can also be used for photocatalysis. ${ }^{80,81}$ In the following example, we have studied three $\mathrm{Pt} / \mathrm{TiO}_{2}$ catalysts with different sizes of $\mathrm{Pt}$ species for photocatalytic $\mathrm{H}_{2}$ evolution from ethanol- $\mathrm{H}_{2} \mathrm{O}$ mixture under UV light.

As shown in Figure 12, all three $\mathrm{Pt} / \mathrm{TiO}_{2}$ catalysts are active for the photocatalytic $\mathrm{H}_{2}$ evolution reaction and the $0.03 \mathrm{Pt}$ /

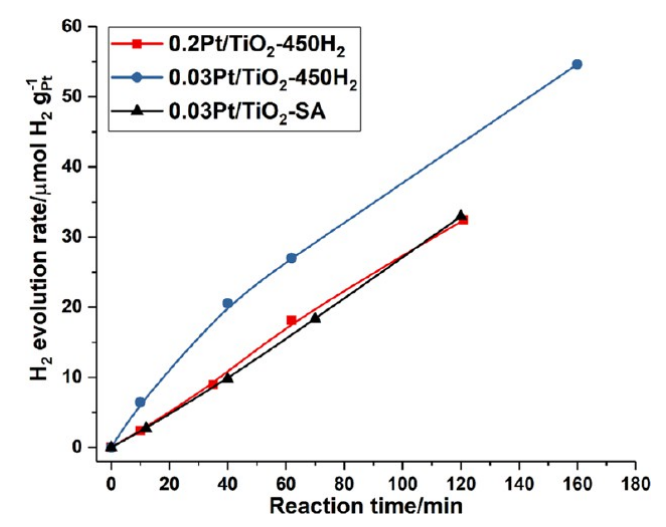

Figure 12. Catalytic performance of $\mathrm{Pt}$ single atoms, clusters, and nanoparticles supported on $\mathrm{TiO}_{2}$ for photocatalytic $\mathrm{H}_{2}$ evolution under UV light. The same amount of solid $\mathrm{Pt} / \mathrm{TiO}_{2}$ catalysts was used as the catalyst, and the $\mathrm{H}_{2}$ evolution rate was normalized to the $\mathrm{Pt}$ mass in different catalysts.
$\mathrm{TiO}_{2}-450 \mathrm{H}_{2}$ sample containing Pt clusters shows the highest activity, while the other two samples show similar activity. The three used $\mathrm{Pt} / \mathrm{TiO}_{2}$ catalysts after the photocatalytic reaction have also been measured by STEM. As presented in Figure 13,
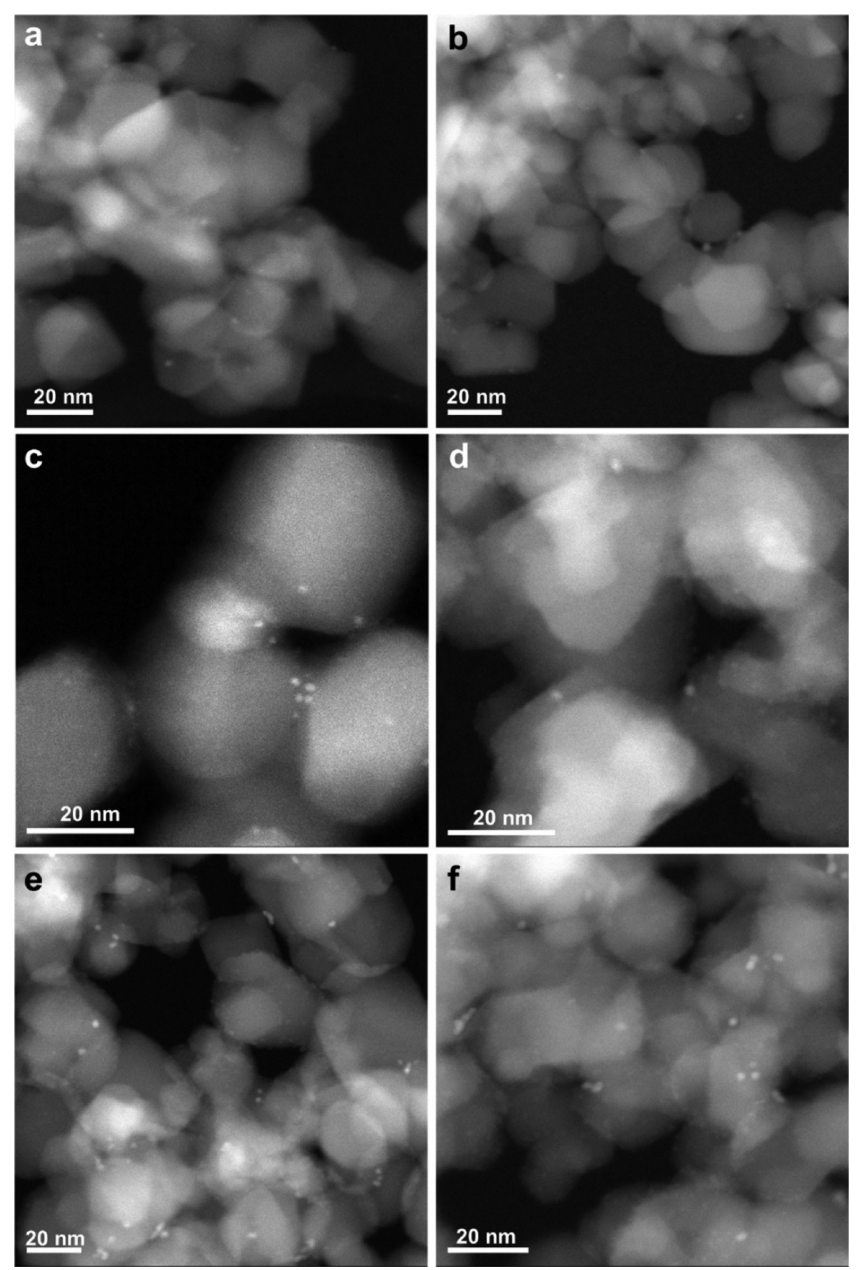

Figure 13. HAADF-STEM images of various $\mathrm{Pt} / \mathrm{TiO}_{2}$ catalysts after the photocatalytic $\mathrm{H}_{2}$ evolution reaction. $(\mathrm{a}, \mathrm{b}) 0.03 \mathrm{Pt} / \mathrm{TiO}_{2}-\mathrm{SA},(\mathrm{c}, \mathrm{d})$ $0.03 \mathrm{Pt} / \mathrm{TiO}_{2}-450 \mathrm{H}_{2}$, and $(\mathrm{e}, \mathrm{f}) \quad 0.2 \mathrm{Pt} / \mathrm{TiO}_{2}-450 \mathrm{H}_{2}$. Pt clusters and nanoparticles are formed in the $0.03 \mathrm{Pt} / \mathrm{TiO}_{2}$-SA sample after the photocatalytic $\mathrm{H}_{2}$ evolution reaction. In the other two cases, the size of Pt clusters and nanoparticles also slightly increases, indicating the instability of Pt species under the photocatalytic reaction conditions.

a large fraction of $\mathrm{Pt}$ nanoparticles and some Pt clusters can be found in the $0.03 \mathrm{Pt} / \mathrm{TiO}_{2}-\mathrm{SA}$ sample, implying the sintering of singly dispersed $\mathrm{Pt}$ atoms under the photocatalytic reaction conditions. In the case of the other two samples, slight sintering is also observed, implying the instability of Pt species during the photocatalytic process under UV light. On the basis of the above results, it can be concluded that Pt clusters and nanoparticles show higher activity when working as cocatalysts for the photocatalytic $\mathrm{H}_{2}$ evolution reaction. Furthermore, singly dispersed $\mathrm{Pt}$ atoms on $\mathrm{TiO}_{2}$ are not stable under the photocatalytic conditions, and their sintering behavior may be associated with the surface reaction (oxidation of ethanol by photogenerated holes and the reduction of $\mathrm{H}^{+}$to $\mathrm{H}_{2}$ by photogenerated electrons) under UV light irradiation. 


\section{CONCLUSIONS}

In summary, the results presented in this work demonstrate that when studying the catalytic properties of highly dispersed heterogeneous metal catalysts containing subnanometric metal species (single atoms or clusters) or small nanoparticles of $\sim 1$ $\mathrm{nm}$, it is critical to characterize the coordination environment of the metal entities by the combination of adequate ex situ and in situ characterization techniques. Furthermore, in terms of single-atom catalysts, the evolution of the atomically dispersed metal species under reaction conditions should also be carefully followed by in situ electron microscopy or spectroscopy techniques, in order to verify the nature of the active sites under reaction conditions. Our results suggest that in a variety of reactions, single atoms can sinter into clusters or nanoparticles during the reaction, and the evolution behavior depends on the metal-support and metal-reactant interactions. Nevertheless, we have found that a small portion of metal clusters or nanoparticles present together with the singleatom species can contribute to the reactivity in a dominant manner, indicating the importance of performing an appropriate comparison between different types of metal entities (from single atoms to clusters and nanoparticles).

\section{ASSOCIATED CONTENT}

\section{S Supporting Information}

The Supporting Information is available free of charge on the ACS Publications website at DOI: 10.1021/acscatal.9b04214.

Experimental details on the sample preparation, characterization, catalytic tests, and additional characterization and catalytic results (PDF)

\section{AUTHOR INFORMATION}

\section{Corresponding Author}

*E-mail: acorma@itq.upv.es. Web: www.avelinocorma.com. ORCID $\odot$

Raul Arenal: 0000-0002-2071-9093

Patricia Concepcion: 0000-0003-2058-3103

Avelino Corma: 0000-0002-2232-3527

\section{Present Address}

IIDepartament d'Enginyeria Química, Universitat Rovira i Virgili, Avinguda dels Paisos Catalans, 26, 43007 Tarragona, Spain.

\section{Notes}

The authors declare no competing financial interest.

\section{ACKNOWLEDGMENTS}

This work has been supported by the European Union through the European Research Council (grant ERC-AdG-2014671093, SynCatMatch) and the Spanish government through the "Severo Ochoa Program" (SEV-2016-0683). L.L. thanks ITQ for providing a contract. The authors also thank Microscopy Service of UPV for the TEM and STEM measurements. This research used resources of the Advanced Photon Source, an Office of Science User Facility operated for the U.S. Department of Energy (DOE) Office of Science by Argonne National Laboratory, and was supported by the U.S. DOE under contract no. DE-AC02-06CH11357 and the Canadian Light Source and its funding partners. The HR STEM and STEM-EELS studies were conducted at the Laboratorio de Microscopias Avanzadas, Universidad de Zaragoza, Spain. R.A. acknowledges support from Spanish
MINECO grant MAT2016-79776-P (AEI/FEDER, UE), from the Government of Aragon and the European Social Fund (grant number E13_17R, FEDER, UE), and from the European Union $\mathrm{H} 20 \overline{20}$ program “ESTEEM3" (grant number 823717). A.V.P. thanks the Spanish Government (Agencia Estatal de Investigación) and the European Union (European Regional Development Fund) for a grant for young researchers (CTQ2015-74138-JIN, AEI/FEDER/UE).

\section{REFERENCES}

(1) Liu, J. Catalysis by Supported Single Metal Atoms. ACS Catal. 2017, 7, 34-59.

(2) Wang, A.; Li, J.; Zhang, T. Heterogeneous Single-Atom Catalysis. Nat. Rev. Chem. 2018, 2, 65-81.

(3) Chen, Y.; Ji, S.; Chen, C.; Peng, Q.; Wang, D.; Li, Y. SingleAtom Catalysts: Synthetic Strategies and Electrochemical Applications. Joule 2018, 2, 1242-1264.

(4) Flytzani-Stephanopoulos, M.; Gates, B. C. Atomically dispersed supported metal catalysts. Annu. Rev. Chem. Biomol. Eng. 2012, 3, 545-574.

(5) Li, X.; Yang, X.; Zhang, J.; Huang, Y.; Liu, B. In Situ/Operando Techniques for Characterization of Single-Atom Catalysts. ACS Catal. 2019, 9, 2521-2531.

(6) Gates, B. C.; Flytzani-Stephanopoulos, M.; Dixon, D. A.; Katz, A. Atomically Dispersed Supported Metal Catalysts: Perspectives and Suggestions for Future Research. Catal. Sci. Technol. 2017, 7, 42594275.

(7) Liu, L.; Corma, A. Metal Catalysts for Heterogeneous Catalysis: From Single Atoms to Nanoclusters and Nanoparticles. Chem. Rev. 2018, 118, 4981-5079.

(8) Yamazoe, S.; Koyasu, K.; Tsukuda, T. Nonscalable Oxidation Catalysis of Gold Clusters. Acc. Chem. Res. 2014, 47, 816-824.

(9) Du, Y.; Sheng, H.; Astruc, D.; Zhu, M. Atomically Precise Noble Metal Nanoclusters as Efficient Catalysts: A Bridge between Structure and Properties. Chem. Rev. 2019, DOI: 10.1021/acs.chemrev.8b00726.

(10) Malta, G.; Kondrat, S. A.; Freakley, S. J.; Davies, C. J.; Lu, L.; Dawson, S.; Thetford, A.; Gibson, E. K.; Morgan, D. J.; Jones, W.; et al. Identification of Single-Site Gold Catalysis in Acetylene Hydrochlorination. Science 2017, 355, 1399-1403.

(11) Chung, H. T.; Cullen, D. A.; Higgins, D.; Sneed, B. T.; Holby, E. F.; More, K. L.; Zelenay, P. Direct Atomic-Level Insight into the Active Sites of a High-Performance PGM-Free ORR Catalyst. Science 2017, 357, 479-484.

(12) Lin, J.; Chen, Y.; Zhou, Y.; Li, L.; Qiao, B.; Wang, A.; Liu, J.; Wang, X.; Zhang, T. More Active Ir Subnanometer Clusters than Single-Atoms for Catalytic Oxidation of $\mathrm{CO}$ at Low Temperature. AIChE J. 2017, 63, 4003-4012.

(13) Herzing, A. A.; Kiely, C. J.; Carley, A. F.; Landon, P.; Hutchings, G. J. Identification of Active Gold Nanoclusters on Iron Oxide Supports for CO Oxidation. Science 2008, 321, 1331-1335.

(14) Qiao, B.; Wang, A.; Yang, X.; Allard, L. F.; Jiang, Z.; Cui, Y.; Liu, J.; Li, J.; Zhang, T. Single-Atom Catalysis of CO Oxidation Using $\mathrm{Pt}_{1} / \mathrm{FeOx}$. Nat. Chem. 2011, 3, 634-641.

(15) DeRita, L.; Dai, S.; Lopez-Zepeda, K.; Pham, N.; Graham, G. W.; Pan, X.; Christopher, P. Catalyst Architecture for Stable Single Atom Dispersion Enables Site-Specific Spectroscopic and Reactivity Measurements of CO Adsorbed to Pt Atoms, Oxidized Pt Clusters, and Metallic Pt Clusters on $\mathrm{TiO}_{2}$. J. Am. Chem. Soc. 2017, 139, 14150-14165.

(16) Jones, J.; Xiong, H.; DeLaRiva, A. T.; Peterson, E. J.; Pham, H.; Challa, S. R.; Qi, G.; Oh, S.; Wiebenga, M. H.; Pereira Hernandez, X. I.; Wang, Y.; Datye, A. K. Thermally Stable Single-Atom Platinum-onCeria Catalysts via Atom Trapping. Science 2016, 353, 150-154.

(17) Ding, K.; Gulec, A.; Johnson, A. M.; Schweitzer, N. M.; Stucky, G. D.; Marks, L. D.; Stair, P. C. Identification of Active Sites in CO Oxidation and Water-Gas Shift over Supported Pt Catalysts. Science 2015, 350, 189-192. 
(18) Qiao, B.; Liu, J.; Wang, Y.-G.; Lin, Q.; Liu, X.; Wang, A.; Li, J.; Zhang, T.; Liu, J. Highly Efficient Catalysis of Preferential Oxidation of $\mathrm{CO}$ in $\mathrm{H}_{2}$-Rich Stream by Gold Single-Atom Catalysts. ACS Catal. 2015, 5, 6249-6254.

(19) Qiao, B.; Liang, J.-X.; Wang, A.; Xu, C.-Q.; Li, J.; Zhang, T.; Liu, J. J. Ultrastable Single-Atom Gold Catalysts with Strong Covalent Metal-Support Interaction (CMSI). Nano Res. 2015, 8, 2913-2924.

(20) Wang, J.; Tan, H.; Yu, S.; Zhou, K. Morphological Effects of Gold Clusters on the Reactivity of Ceria Surface Oxygen. ACS Catal. 2015, 5, 2873-2881.

(21) Guo, L.-W.; Du, P.-P.; Fu, X.-P.; Ma, C.; Zeng, J.; Si, R.; Huang, Y. Y.; Jia, C. J.; Zhang, Y. W.; Yan, C. H. Contributions of Distinct Gold Species to Catalytic Reactivity for Carbon Monoxide Oxidation. Nat. Commun. 2016, 7, 13481.

(22) Wei, H.; Liu, X.; Wang, A.; Zhang, L.; Qiao, B.; Yang, X.; Huang, Y.; Miao, S.; Liu, J.; Zhang, T. FeOx-Supported Platinum Single-Atom and Pseudo-Single-Atom Catalysts for Chemoselective Hydrogenation of Functionalized Nitroarenes. Nat. Commun. 2014, 5, 5634.

(23) Zhang, B.; Asakura, H.; Zhang, J.; Zhang, J.; De, S.; Yan, N. Stabilizing a Platinum1 Single-Atom Catalyst on Supported Phosphomolybdic Acid without Compromising Hydrogenation Activity. Angew. Chem., Int. Ed. 2016, 55, 8319-8323.

(24) Vilé, G.; Albani, D.; Nachtegaal, M.; Chen, Z.; Dontsova, D.; Antonietti, M.; López, N.; Pérez-Ramírez, J. A Stable Single-Site Palladium Catalyst for Hydrogenations. Angew. Chem., Int. Ed. 2015, 54, 11265-11269.

(25) Liu, P.; Zhao, Y.; Qin, R.; Mo, S.; Chen, G.; Gu, L.; Chevrier, D. M.; Zhang, P.; Guo, Q.; Zang, D.; Wu, B.; Fu, G.; Zheng, N. Photochemical Route for Synthesizing Atomically Dispersed Palladium Catalysts. Science 2016, 352, 797-800.

(26) Rossell, M. D.; Caparrós, F. J.; Angurell, I.; Muller, G.; Llorca, J.; Seco, M.; Rossell, O. Magnetite-Supported Palladium Single-Atoms Do Not Catalyse the Hydrogenation of Alkenes but Small Clusters Do. Catal. Sci. Technol. 2016, 6, 4081-4085.

(27) Boronat, M.; Leyva-Pérez, A.; Corma, A. Theoretical and Experimental Insights into the Origin of the Catalytic Activity of Subnanometric Gold Clusters: Attempts to Predict Reactivity with Clusters and Nanoparticles of Gold. Acc. Chem. Res. 2014, 47, 834844.

(28) Vajda, S.; White, M. G. Catalysis Applications of Size-Selected Cluster Deposition. ACS Catal. 2015, 5, 7152-7176.

(29) Gates, B. C. Supported Metal Clusters: Synthesis, Structure, and Catalysis. Chem. Rev. 1995, 95, 511-522.

(30) Corma, A.; Concepción, P.; Boronat, M.; Sabater, M. J.; Navas, J.; Yacaman, M. J.; Larios, E.; Posadas, A.; López-Quintela, M. A.; Buceta, D.; Mendoza, E.; Guilera, G.; Mayoral, A. Exceptional Oxidation Activity with Size-Controlled Supported Gold Clusters of Low Atomicity. Nat. Chem. 2013, 5, 775-781.

(31) Oliver-Meseguer, J.; Liu, L.; Garcia-Garcia, S.; Canos-Gimenez, C.; Dominguez, I.; Gavara, R.; Domenech-Carbo, A.; Concepcion, P.; Leyva-Perez, A.; Corma, A. Stabilized naked sub-nanometric $\mathrm{Cu}$ clusters within a polymeric film catalyze C-N, C-C, C-O, C-S, and C$\mathrm{P}$ bond-forming reactions. J. Am. Chem. Soc. 2015, 137, 3894-3900.

(32) Hoffman, A. S.; Debefve, L. M.; Zhang, S.; Perez-Aguilar, J. E.; Conley, E. T.; Justl, K. R.; Arslan, I.; Dixon, D. A.; Gates, B. C. Beating Heterogeneity of Single-Site Catalysts: $\mathrm{MgO}$-Supported Iridium Complexes. ACS Catal. 2018, 8, 3489-3498.

(33) He, Q.; Freakley, S. J.; Edwards, J. K.; Carley, A. F.; Borisevich, A. Y.; Mineo, Y.; Haruta, M.; Hutchings, G. J.; Kiely, C. J. Population and Hierarchy of Active Species in Gold Iron Oxide Catalysts for Carbon Monoxide Oxidation. Nat. Commun. 2016, 7, 12905.

(34) Liu, L.; Zakharov, D. N.; Arenal, R.; Concepcion, P.; Stach, E. A.; Corma, A. Evolution and Stabilization of Subnanometric Metal Species in Confined Space by in situ TEM. Nat. Commun. 2018, 9, 574.

(35) Moliner, M.; Gabay, J. E.; Kliewer, C. E.; Carr, R. T.; Guzman, J.; Casty, G. L.; Serna, P.; Corma, A. Reversible Transformation of Pt
Nanoparticles into Single Atoms inside High-Silica Chabazite Zeolite. J. Am. Chem. Soc. 2016, 138, 15743-15750.

(36) Hartfelder, U.; Kartusch, C.; Makosch, M.; Rovezzi, M.; Sá, J.; van Bokhoven, J. A. Particle Size and Support Effects in Hydrogenation over Supported Gold Catalysts. Catal. Sci. Technol. 2013, 3, 454-461.

(37) Zhao, F.; Ikushima, Y.; Arai, M. Hydrogenation of Nitrobenzene with Supported Platinum Catalysts in Supercritical Carbon Dioxide: Effects of Pressure, Solvent, and Metal Particle Size. J. Catal. 2004, 224, 479-483.

(38) Coq, B.; Tijani, A.; Figuéras, F. Particle Size Effect on the Kinetics of p-Chloronitrobenzene Hydrogenation over Platinum/ Alumina Catalysts. J. Mol. Catal. 1991, 68, 331-345.

(39) Lyu, J.; Wang, J.; Lu, C.; Ma, L.; Zhang, Q.; He, X.; Li, X. SizeDependent Halogenated Nitrobenzene Hydrogenation Selectivity of Pd Nanoparticles. J. Phys. Chem. C 2014, 118, 2594-2601.

(40) Corma, A.; Serna, P.; Concepción, P.; Calvino, J. J. Transforming Nonselective into Chemoselective Metal Catalysts for the Hydrogenation of Substituted Nitroaromatics. J. Am. Chem. Soc. 2008, 130, 8748-8753.

(41) Arenal, R.; March, K.; Ewels, C. P.; Rocquefelte, X.; Kociak, M.; Loiseau, A.; Stéphan, O. Atomic Configuration of Nitrogen-Doped Single-Walled Carbon Nanotubes. Nano Lett. 2014, 14, 5509-5516.

(42) Liu, L.; Díaz, U.; Agostini, G.; Concepción, P.; Corma, A. Generation of Subnanometric Platinum with High Stability during Transformation of a 2D Zeolite into 3D. Nat. Mater. 2017, 16, 132138

(43) Vargas, J. A.; Petkov, V.; Nouh, E. S. A.; Ramamoorthy, R. K.; Lacroix, L.-M.; Poteau, R.; Viau, G.; Lecante, P.; Arenal, R. Ultrathin Gold Nanowires with the Polytetrahedral Structure of Bulk Manganese. ACS Nano 2018, 12, 9521-9531.

(44) Serna, P.; Concepción, P.; Corma, A. Design of highly active and chemoselective bimetallic gold-platinum hydrogenation catalysts through kinetic and isotopic studies. J. Catal. 2009, 265, 19-25.

(45) Vorobyeva, E.; Fako, E.; Chen, Z.; Collins, S. M.; Johnstone, D.; Midgley, P. A.; Hauert, R.; Safonova, O. V.; Vilé, G.; López, N.; Mitchell, S.; Pérez-Ramírez, J. Atom-by-Atom Resolution of Structure-Function Relations over Low-Nuclearity Metal Catalysts. Angew. Chem., Int. Ed. 2019, 58, 8724-8729.

(46) Lykhach, Y.; Kozlov, S. M.; Skála, T.; Tovt, A.; Stetsovych, V.; Tsud, N.; Dvořák, F.; Johánek, V.; Neitzel, A.; Mysliveček, J.; Fabris, S.; Matolín, V.; Neyman, K. M.; Libuda, J. Counting electrons on supported nanoparticles. Nat. Mater. 2016, 15, 284.

(47) $\mathrm{Fu}, \mathrm{Q}$.; Wagner, T. Interaction of nanostructured metal overlayers with oxide surfaces. Surf. Sci. Rep. 2007, 62, 431-498.

(48) Moses-DeBusk, M.; Yoon, M.; Allard, L. F.; Mullins, D. R.; Wu, Z.; Yang, X.; Veith, G.; Stocks, G. M.; Narula, C. K. CO oxidation on supported single $\mathrm{Pt}$ atoms: experimental and ab initio density functional studies of $\mathrm{CO}$ interaction with $\mathrm{Pt}$ atom on theta$\mathrm{Al}_{2} \mathrm{O}_{3}(010)$ surface. J. Am. Chem. Soc. 2013, 135, 12634-12645.

(49) Sanchez, S. I.; Menard, L. D.; Bram, A.; Kang, J. H.; Small, M. W.; Nuzzo, R. G.; Frenkel, A. I. The Emergence of Nonbulk Properties in Supported Metal Clusters: Negative Thermal Expansion and Atomic Disorder in Pt Nanoclusters Supported on gmma- $\mathrm{Al}_{2} \mathrm{O}_{3}$. J. Am. Chem. Soc. 2009, 131, 7040-7054.

(50) Derevyannikova, E. A.; Kardash, T. Y.; Stadnichenko, A. I.; Stonkus, O. A.; Slavinskaya, E. M.; Svetlichnyi, V. A.; Boronin, A. I. Structural Insight into Strong $\mathrm{Pt}-\mathrm{CeO}_{2}$ Interaction: From Single $\mathrm{Pt}$ Atoms to PtOx Clusters. J. Phys. Chem. C 2018, 123, 1320-1334.

(51) Jiang, Z.; Sun, Z.; Yang, Y.; Chen, S.; Shangguan, W.; Wu, X. The Role of Metal Oxide Interactions: Revisiting Pt Growth on the $\mathrm{TiO}_{2}$ Surface in the Process of Impregnation Method. Nanoscale 2017, 9, 14272-14279.

(52) Cheng, X.; Li, Y.; Zheng, L.; Yan, Y.; Zhang, Y.; Chen, G.; Sun, S.; Zhang, J. Highly Active, Stable Oxidized Platinum Clusters as Electrocatalysts for the Hydrogen Evolution Reaction. Energy Environ. Sci. 2017, 10, 2450-2458.

(53) Ahmadi, M.; Timoshenko, J.; Behafarid, F.; Roldan Cuenya, B. Tuning the Structure of $\mathrm{Pt}$ Nanoparticles through Support 
Interactions: An in Situ Polarized X-ray Absorption Study Coupled with Atomistic Simulations. J. Phys. Chem. C 2019, 123, 1066610676.

(54) Cui, X.; Junge, K.; Dai, X.; Kreyenschulte, C.; Pohl, M.-M.; Wohlrab, S.; Shi, F.; Brückner, A.; Beller, M. Synthesis of Single Atom Based Heterogeneous Platinum Catalysts: High Selectivity and Activity for Hydrosilylation Reactions. ACS Cent. Sci. 2017, 3, 580585.

(55) Zhang, Z.; Zhu, Y.; Asakura, H.; Zhang, B.; Zhang, J.; Zhou, M.; Han, Y.; Tanaka, T.; Wang, A.; Zhang, T.; Yan, N. Thermally Stable Single Atom $\mathrm{Pt} / \mathrm{m}-\mathrm{Al}_{2} \mathrm{O}_{3}$ for Selective Hydrogenation and $\mathrm{CO}$ Oxidation. Nat. Commun. 2017, 8, 16100.

(56) Song, H.; Rioux, R. M.; Hoefelmeyer, J. D.; Komor, R.; Niesz, K.; Grass, M.; Yang, P.; Somorjai, G. A. Hydrothermal Growth of Mesoporous SBA-15 Silica in the Presence of PVP-Stabilized Pt Nanoparticles: Synthesis, Characterization, and Catalytic Properties. J. Am. Chem. Soc. 2006, 128, 3027-3037.

(57) Claus, P.; Brückner, A.; Mohr, C.; Hofmeister, H. Supported Gold Nanoparticles from Quantum Dot to Mesoscopic Size Scale: Effect of Electronic and Structural Properties on Catalytic Hydrogenation of Conjugated Functional Groups. J. Am. Chem. Soc. 2000, 122, 11430-11439.

(58) Gracia, F. J.; Miller, J. T.; Kropf, A. J.; Wolf, E. E. Kinetics, FTIR, and Controlled Atmosphere EXAFS Study of the Effect of Chlorine on Pt-Supported Catalysts during Oxidation Reactions. J. Catal. 2002, 209, 341-354.

(59) Ankudinov, A. L.; Rehr, J. J.; Bare, S. R. Hybridization Peaks in Pt-Cl XANES. Chem. Phys. Lett. 2000, 316, 495-500.

(60) Dessal, C.; Len, T.; Morfin, F.; Rousset, J.-L.; Aouine, M.; Afanasiev, P.; Piccolo, L. Dynamics of Single Pt Atoms on Alumina During CO Oxidation Monitored by Operando X-ray and Infrared Spectroscopies. ACS Catal. 2019, 9, 5752-5759.

(61) Bliem, R.; van der Hoeven, J. E. S.; Hulva, J.; Pavelec, J.; Gamba, O.; de Jongh, P. E.; Schmid, M.; Blaha, P.; Diebold, U.; Parkinson, G. S. Dual Role of $\mathrm{CO}$ in the Stability of Subnano Pt Clusters at the $\mathrm{Fe}_{3} \mathrm{O}_{4}(001)$ Surface. Proc. Natl. Acad. Sci. U.S.A. 2016, 113, 8921-8926.

(62) Parkinson, G. S.; Novotny, Z.; Argentero, G.; Schmid, M.; Pavelec, J.; Kosak, R.; Blaha, P.; Diebold, U. Carbon MonoxideInduced Adatom Sintering in a $\mathrm{Pd}-\mathrm{Fe}_{3} \mathrm{O}_{4}$ Model Catalyst. Nat. Mater. 2013, 12, 724.

(63) Campbell, C. T. The Energetics of Supported Metal Nanoparticles: Relationships to Sintering Rates and Catalytic Activity. Acc. Chem. Res. 2013, 46, 1712-1719.

(64) Pereira-Hernández, X. I.; DeLaRiva, A.; Muravev, V.; Kunwar, D.; Xiong, H.; Sudduth, B.; Engelhard, M.; Kovarik, L.; Hensen, E. J. M.; Wang, Y.; et al. Tuning Pt- $\mathrm{CeO}_{2}$ Interactions by HighTemperature Vapor-Phase Synthesis for Improved Reducibility of Lattice Oxygen. Nat. Commun. 2019, 10, 1358.

(65) Ahmadi, M.; Mistry, H.; Roldan Cuenya, B. Tailoring the Catalytic Properties of Metal Nanoparticles via Support Interactions. J. Phys. Chem. Lett. 2016, 7, 3519-3533.

(66) Lou, Y.; Liu, J. CO Oxidation on Metal Oxide Supported Single Pt atoms: The Role of the Support. Ind. Eng. Chem. Res. 2017, 56, 6916-6925.

(67) Liu, H.-H.; Wang, Y.; Jia, A.-P.; Wang, S.-Y.; Luo, M.-F.; Lu, J.Q. Oxygen Vacancy Promoted $\mathrm{CO}$ Oxidation over $\mathrm{Pt} / \mathrm{CeO}_{2}$ Catalysts: A Reaction at $\mathrm{Pt}-\mathrm{CeO}_{2}$ Interface. Appl. Surf. Sci. 2014, 314, 725-734.

(68) Artiglia, L.; Orlando, F.; Roy, K.; Kopelent, R.; Safonova, O.; Nachtegaal, M.; Huthwelker, T.; van Bokhoven, J. A. Introducing Time Resolution to Detect $\mathrm{Ce}^{3+}$ Catalytically Active Sites at the $\mathrm{Pt} /$ $\mathrm{CeO}_{2}$ Interface through Ambient Pressure X-ray Photoelectron Spectroscopy. J. Phys. Chem. Lett. 2017, 8, 102-108.

(69) Liu, L.; Matsushita, T.; Concepción, P.; Leyva-Pérez, A.; Corma, A. Facile Synthesis of Surface-Clean Monodispersed CuOx Nanoparticles and Their Catalytic Properties for Oxidative Coupling of Alkynes. ACS Catal. 2016, 6, 2211.
(70) Fernández, E.; Boronat, M.; Corma, A. Trends in the Reactivity of Molecular $\mathrm{O}_{2}$ with Copper Clusters: Influence of Size and Shape. J. Phys. Chem. C 2015, 119, 19832-19846.

(71) Laletina, S. S.; Mamatkulov, M.; Shor, E. A.; Kaichev, V. V.; Genest, A.; Yudanov, I. V.; Rösch, N. Size-Dependence of the Adsorption Energy of $\mathrm{CO}$ on $\mathrm{Pt}$ Nanoparticles: Tracing Two Intersecting Trends by DFT Calculations. J. Phys. Chem. C 2017, $121,17371-17377$.

(72) Allian, A. D.; Takanabe, K.; Fujdala, K. L.; Hao, X.; Truex, T. J.; Cai, J.; Buda, C.; Neurock, M.; Iglesia, E. Chemisorption of $\mathrm{CO}$ and Mechanism of CO Oxidation on Supported Platinum Nanoclusters. J. Am. Chem. Soc. 2011, 133, 4498-4517.

(73) Cargnello, M.; Doan-Nguyen, V. V. T.; Gordon, T. R.; Diaz, R. E.; Stach, E. A.; Gorte, R. J.; Fornasiero, P.; Murray, C. B. Control of Metal Nanocrystal Size Reveals Metal-Support Interface Role for Ceria Catalysts. Science 2013, 341, 771-773.

(74) Liu, A.; Liu, X.; Liu, L.; Pu, Y.; Guo, K.; Tan, W.; Gao, S.; Luo, Y.; Yu, S.; Si, R.; et al. Getting Insights into the Temperature-Specific Active Sites on Platinum Nanoparticles for CO Oxidation: A Combined in Situ Spectroscopic and ab Initio Density Functional Theory Study. ACS Catal. 2019, 9, 7759-7768.

(75) Zhu, J.; Yang, M.-L.; Yu, Y.; Zhu, Y.-A.; Sui, Z.-J.; Zhou, X.-G.; Holmen, A.; Chen, D. Size-Dependent Reaction Mechanism and Kinetics for Propane Dehydrogenation over Pt Catalysts. ACS Catal. 2015, 5, 6310-6319.

(76) Xiong, H.; Lin, S.; Goetze, J.; Pletcher, P.; Guo, H.; Kovarik, L.; Artyushkova, K.; Weckhuysen, B. M.; Datye, A. K. Thermally Stable and Regenerable Platinum-Tin Clusters for Propane Dehydrogenation Prepared by Atom Trapping on Ceria. Angew. Chem., Int. Ed. 2017, 56, 8986-8991.

(77) Yang, J.; Wang, D.; Han, H.; Li, C. Roles of Cocatalysts in Photocatalysis and Photoelectrocatalysis. Acc. Chem. Res. 2013, 46, 1900-1909.

(78) Berr, M. J.; Schweinberger, F. F.; Döblinger, M.; Sanwald, K. E.; Wolff, C.; Breimeier, J.; Crampton, A. S.; Ridge, C. J.; Tschurl, M.; Heiz, U.; et al. Size-Selected Subnanometer Cluster Catalysts on Semiconductor Nanocrystal Films for Atomic Scale Insight into Photocatalysis. Nano Lett. 2012, 12, 5903-5906.

(79) Schweinberger, F. F.; Berr, M. J.; Döblinger, M.; Wolff, C.; Sanwald, K. E.; Crampton, A. S.; Ridge, C. J.; Jäckel, F.; Feldmann, J.; Tschurl, M.; et al. Cluster Size Effects in the Photocatalytic Hydrogen Evolution Reaction. J. Am. Chem. Soc. 2013, 135, 13262-13265.

(80) Xing, J.; Chen, J. F.; Li, Y. H.; Yuan, W. T.; Zhou, Y.; Zheng, L. R.; Wang, H. F.; Hu, P.; Wang, Y.; Zhao, H. J.; et al. Stable Isolated Metal Atoms as Active Sites for Photocatalytic Hydrogen Evolution. Chem.-Eur. J. 2014, 20, 2138-2144.

(81) Li, X.; Bi, W.; Zhang, L.; Tao, S.; Chu, W.; Zhang, Q.; Luo, Y.; $\mathrm{Wu}$, C.; Xie, Y. Single-Atom Pt as Co-Catalyst for Enhanced Photocatalytic $\mathrm{H}_{2}$ Evolution. Adv. Mater. 2016, 28, 2427-2431. 